\title{
Cell-Specific Expression of Connexins and Evidence of Restricted Gap Junctional Coupling between Glial Cells and between Neurons
}

\author{
John E. Rash, ${ }^{1,2}$ Thomas Yasumura, ${ }^{1}$ F. Edward Dudek, ${ }^{1,2}$ and James I. Nagy ${ }^{3}$ \\ ${ }^{1}$ Department of Anatomy and Neurobiology and 2Program in Molecular, Cellular, and Integrative Neurosciences, Colorado \\ State University, Fort Collins, Colorado 80523, and ${ }^{3}$ Department of Physiology, Faculty of Medicine, University of \\ Manitoba, Winnipeg, Manitoba, Canada R3E 3J7
}

The transmembrane connexin proteins of gap junctions link extracellularly to form channels for cell-to-cell exchange of ions and small molecules. Two primary hypotheses of gap junction coupling in the CNS are the following: (1) generalized coupling occurs between neurons and glia, with some connexins expressed in both neurons and glia, and (2) intercellular junctional coupling is restricted to specific coupling partners, with different connexins expressed in each cell type. There is consensus that gap junctions link neurons to neurons and astrocytes to oligodendrocytes, ependymocytes, and other astrocytes. However, unresolved are the existence and degree to which gap junctions occur between oligodendrocytes, between oligodendrocytes and neurons, and between astrocytes and neurons. Using light microscopic immunocytochemistry and freezefracture replica immunogold labeling of adult rat CNS, we investigated whether four of the best-characterized CNS con- nexins are each present in one or more cell types, whether oligodendrocytes also share gap junctions with other oligodendrocytes or with neurons, and whether astrocytes share gap junctions with neurons. Connexin32 (Cx32) was found only in gap junctions of oligodendrocyte plasma membranes, Cx30 and $\mathrm{C} \times 43$ were found only in astrocyte membranes, and Cx36 was only in neurons. Oligodendrocytes shared intercellular gap junctions only with astrocytes, with each oligodendrocyte isolated from other oligodendrocytes except via astrocyte intermediaries. Finally, neurons shared gap junctions only with other neurons and not with glial cells. Thus, the different cell types of the CNS express different connexins, which define separate pathways for neuronal versus glial gap junctional communication.

Key words: astrocyte; connexin; connexon; gap junction; neuron; oligodendrocyte
Astrocytes, ependymocytes, and oligodendrocytes, the macroglial cells of the adult CNS, are richly invested with gap junctions. Astrocytes, in particular, share gap junctions with all three macroglia, thereby creating a functional panglial syncytium (Mugnaini, 1986; Rash et al., 1997). In contrast, gap junctions involving neurons were reported to be rare (Brightman and Reese, 1969; Sotelo and Korn, 1978), with glial gap junctions greatly outnumbering neuronal gap junctions and neuron-to-glial junctions not detected (Wolff et al., 1998; Rash et al., 2000). The initial "restricted coupling partner" hypothesis that oligodendrocytes share intercellular gap junctions only with astrocytes and that neurons share gap junctions only with neurons (Massa and Mugnaini, 1982; Mugnaini, 1986; Rash et al., 1997) was supported by immunocytochemical data showing that neurons and glia express different connexins (Li et al., 1997; Condorelli et al., 1998; Nagy et al., 1999; Nagy and Rash, 2000; Rash et al., 2000). A quite different "shared-connexins/mixed-coupling" hypothesis, which arose from in situ hybridization, imaging of calcium waves, electrical and dye coupling, and immunocytochemistry, suggests that

\footnotetext{
Received Oct. 27, 2000; revised Jan. 2, 2001; accepted Jan. 3, 2001.

This work was supported by National Institutes of Health Grants NS-31027, NS-39040, and NS-38121 to J.E.R. and MH-59995 to F.E.D. and by grants from the Canadian Institutes of Health Research to J.I.N. We thank G. Stelmack and D. Patel for biochemical and anatomical support in antibody analysis and Kimberly Davidson for quantitative analysis of labeled replicas and photographic assistance.

Higher-resolution images and additional supporting data may be viewed at http:// www.cvmbs.colostate.edu/rashlab.

Correspondence should be addressed to Dr. John E. Rash, Department of Anatomy and Neurobiology, Colorado State University, Fort Collins, CO 80523. E-mail: jrash@cvmbs.colostate.edu.

Copyright (C) 2001 Society for Neuroscience 0270-6474/01/211983-18\$15.00/0
}

neurons and glia coexpress connexin32 (Cx32) and $\mathrm{Cx} 43$, that neuron-to-neuron and neuron-to-glial gap junctions are abundant, and that oligodendrocytes share gap junctions with other oligodendrocytes (Micevych and Abelson, 1991; Nedergaard, 1994; Micevych et al., 1996; Nadarajah et al., 1996; AlvarezMaubecin et al., 2000; for review, see Dermietzel, 1998; Dermietzel and Spray, 1998). However, functional coupling of neurons to glia via gap junctions has been challenged on the basis of the demonstration of alternative signaling mechanisms between these cells (Parpura et al., 1994; Hassinger et al., 1995; Charles et al., 1996; Dudek et al., 1998). Moreover, the limited resolution of light microscopy in tissue slices $(\sim 0.3-0.5 \mu \mathrm{m})$ precludes its use for assigning connexins to plasma membranes of either of two apposed cells or to intervening unresolved cell processes. Likewise, with thin-section electron microscopy (TEM), identification of close plasma membrane appositions as gap junctions is particularly difficult in the CNS unless strict criteria for identifying gap junctions are rigorously applied (Brightman and Reese, 1969; Sloper, 1972; Berdan et al., 1987; Rash et al., 1998a). Although unambiguous labeling of identified gap junctions in identified glial cells has been demonstrated (Li et al., 1997; Nagy et al., 1999), TEM sampling methods limit quantitative analysis of rare coupling combinations.

Freeze-fracture replica immunogold labeling [FRIL; introduced by Fujimoto (1995)] now makes it possible to determine whether specific connexins are present or absent in ultrastructurally defined gap junctions in unambiguously identified neurons and glia (Rash and Yasumura, 1999; Rash et al., 2000). Using antibodies against four well characterized CNS connexins (Cx30, 
Table 1. Antibodies used for freeze-fracture immunogold labeling

\begin{tabular}{llll} 
Antibody & Type & Epitope; designation & Reference; source \\
\hline Connexin 30 & Polyclonal & C terminal; 71-2200 et al., 1999; Zymed \\
Connexin 30 & Monoclonal & C terminal; 33-2500 & Zymed \\
Connexin 32 & Monoclonal & aa 235-246; 7C7 & Li et al., 1997 \\
Connexin 32 & Monoclonal & aa 224-234; 92B & Li et al., 1997 \\
Connexin 32 & Monoclonal & Cytoplasmic loop; 2A-2C2 & Zymed \\
Connexin 32 & Polyclonal & aa 110-128; AB1721 & Chemicon \\
Connexin 32 & Polyclonal & aa 265-279; C3470 & Sigma \\
Connexin 32 & Polyclonal & Cytoplasmic loop; 71-0600 & Zymed \\
Connexin 32 & Polyclonal & Cytoplasmic loop; 2260-1059 & Biogenesis \\
Connexin 36 & Polyclonal & Cytoplasmic loop; Ab51-6200 & Rash et al., 2000; Zymed \\
Connexin 36 & Polyclonal & C terminal; AB51-6300 & Rash et al., 2000: Zymed \\
Connexin 43 & Polyclonal & aa 252-270; AB1727 & Chemicon \\
Connexin 43 & Polyclonal & aa 252-270; MAB3068 & Yamamoto et al., 1990b \\
Connexin 43 & Monoclonal & & Chemicon
\end{tabular}

Cx32, Cx36, and Cx43), in combination with LM immunocytochemistry and FRIL, we show that gap junctions in astrocytes, oligodendrocytes, and neurons have distinctive, nonshared complements of these connexins. On the basis of cell-specific connexin distributions and correlative ultrastructural features, we establish that oligodendrocytes share intercellular gap junctions only with astrocytes and not detectably with other oligodendrocytes. Furthermore, we establish that neurons share gap junctions with neurons and not detectably with oligodendrocytes or astrocytes. These data provide further support for the hypothesis of restricted connexin expression and restricted gap junctioncoupling pathways in neurons and in glia.

\section{MATERIALS AND METHODS}

Antibodies. Anti-connexin antibodies used in this study (Table 1) include 12 monoclonal and polyclonal antibodies against $\mathrm{Cx} 30, \mathrm{Cx} 32$, and $\mathrm{Cx} 43$, plus two well characterized rabbit polyclonal antibodies against Cx36 (Rash et al., 2000). In LM studies, oligodendrocytes were identified by the antibody against the oligodendrocyte/myelin marker $2^{\prime}, 3^{\prime}$-cyclic nucleotide 3'-phosphodiesterase [CNPase; courtesy of Dr. P. Braun, McGill University, Montreal, Quebec, Canada; methods in Li et al. (1997)]. In FRIL studies, identification of astrocyte plasma membranes was confirmed with anti-aquaporin4 (AQP4) antibody, which labels AQP4 "square arrays" that are restricted to astrocyte and ependymocyte plasma membranes (Nielsen et al., 1997; Rash et al., 1998b). In various combinations (Table 2), these antibodies allowed single, double, and triple labeling by FRIL, thereby facilitating both connexin localizations and cell identifications. Double and triple labeling were used to document the presence of one or two connexins in one class of gap junctions, while simultaneously documenting the presence or absence of a third connexin in the same gap junctions or in gap junctions of other cell types. Because both neurons and glia also are reported to express Cx32 (Nadarajah et al., 1996; Dermietzel, 1998; Dermietzel and Spray, 1998; Alvarez-Maubecin et al., 2000), we tested seven anti-Cx32 antibodies by FRIL. However, for comparison with the antibodies most commonly used by other investigators, images of Cx32 labeling by LM and FRIL are shown only from samples labeled with monoclonal antibodies 7C7 and $2 \mathrm{C} 2$. The specificities of these latter two antibodies have been documented (Li et al., 1997). In addition, the usefulness of a newly developed monoclonal anti-Cx30 antibody (33-2500; Zymed, San Francisco, CA) is demonstrated.

Western blots. Male Sprague Dawley rats (300-350 gm) were decapitated, and brain regions were dissected on ice and stored at $-80^{\circ} \mathrm{C}$ until use. Tissues were homogenized in ice-cold $40 \mathrm{~mm}$ Tris- $\mathrm{HCl}$ buffer, $\mathrm{pH}$ 7.4, containing 1\% NP-40 detergent, $1 \mathrm{~mm}$ phenylmethylsulfonyl fluoride (PMSF), and aprotinin, leupeptin, and pepstatin A each at $5 \mu \mathrm{g} / \mathrm{ml}$. For tissues used in immunoblots probed with anti-Cx43 antibody, homoge-
Table 2. Combinations of connexins tested and number of FRIL replicas examined

Connexin labeling Number of replicas ${ }^{\mathrm{a}}$

Single labels ${ }^{\mathrm{b}}$

$\mathrm{C} \times 30$

$\mathrm{C} \times 32$

$\mathrm{Cx} 36$

$\mathrm{Cx} 43$

Double labels

Cx30/Cx32

$\mathrm{Cx} 30 / \mathrm{Cx} 36$

$\mathrm{Cx} 30 / \mathrm{Cx} 43$

$\mathrm{Cx} 32 / \mathrm{Cx} 36$

$\mathrm{Cx} 32 / \mathrm{Cx} 43$

$\mathrm{Cx} 36 / \mathrm{Cx} 43$

\section{6}

3

14

17

Triple labels

$\mathrm{Cx} 30 / \mathrm{Cx} 32 / \mathrm{Cx} 43$

$\mathrm{Cx} 30 / \mathrm{Cx} 32 / \mathrm{Cx} 36$

$\mathrm{Cx} 30 / \mathrm{Cx} 36 / \mathrm{Cx} 43$

Total

303

asemiquantitative data regarding connexin composition of gap junctions were obtained from 37 replicas of spinal cord, 30 of inferior olive, 21 of suprachiasmatic nucleus, 13 of retina, 10 of hippocampus, 8 of paraventricular nucleus, 7 of cerebellum, and 3 of supraoptic nucleus.

bome samples listed as single- or double-labeled for connexins were also labeled for AQP4.

nization buffer was further supplemented with the phosphatase inhibitors sodium orthovanadate and sodium fluoride at 1 and $10 \mathrm{~mm}$ concentrations, respectively. After homogenization, samples were sonicated for 20 sec. Total protein was determined with the Bio-Rad (Hercules, CA) DC protein assay. Proteins were resolved by SDS-PAGE, and gel percentage was varied according to the connexin to be detected by immunoblotting (9\% gels for $\mathrm{Cx} 43,12.5 \%$ gels for $\mathrm{Cx} 30$, and $15 \%$ gels for $\mathrm{Cx} 32$ ). Before being loaded onto gels, samples probed for $\mathrm{Cx} 43$ were boiled in sample buffer, whereas those probed for $\mathrm{Cx} 30$ or $\mathrm{Cx} 32$ were applied without boiling. Resolved proteins were transferred to $0.2 \mu \mathrm{m}$ polyvinylidene difluoride membranes (Bio-Rad) in transfer buffer [ $25 \mathrm{~mm}$ Tris, $192 \mathrm{~mm}$ glycine, and $20 \%(\mathrm{v} / \mathrm{v})$ methanol] containing $0.05 \%$ SDS. Membranes were blocked for $2-3 \mathrm{hr}$ at $22^{\circ} \mathrm{C}$ in $20 \mathrm{~mm}$ Tris, $\mathrm{pH} 7.4,150 \mathrm{~mm} \mathrm{NaCl}$, and $0.2 \%$ Tween 20 (TBS-T) containing $5 \%$ skim milk powder and incubated with primary antibody for $12-16 \mathrm{hr}$ at $4^{\circ} \mathrm{C}$ in TBS-T containing $1 \%$ skim milk powder. All primary antibodies were used at a concentration of 1 $\mu \mathrm{g} / \mathrm{ml}$, except anti-Cx32 (Sigma, St. Louis, MO), which was used at 0.33 $\mu \mathrm{g} / \mathrm{ml}$, and anti-Cx43 (18A), which was used at a dilution of 1:35,000. 
After incubation with primary antibody, membranes were washed for 40 min in TBS-T and then incubated for $1 \mathrm{hr}$ at room temperature in TBS-T containing $1 \%$ skim milk powder and either anti-rabbit or anti-mouse horseradish peroxidase-conjugated secondary antibody at dilutions of 1:5000 or 1:3000, respectively. Blots were washed in TBS-T and then incubated for 1 min with ECL chemiluminescence reagents (Amersham Pharmacia Biotech, Piscataway, NJ).

Immunohistochemistry for light microscopy. A newly generated monoclonal anti-Cx30 antibody (Zymed 33-2500) was initially tested for use in immunohistochemistry by peroxidase anti-peroxidase methods used previously in studies of a polyclonal Cx30 antibody (Nagy et al., 1999). For double-immunofluorescence studies, rats were deeply anesthetized with equithesin and perfused transcardially with $50 \mathrm{ml}$ of prefixative solution consisting of cold $\left(4^{\circ} \mathrm{C}\right) 0.1 \mathrm{~m}$ sodium phosphate buffer (PB), $\mathrm{pH} 7.4$, containing $0.9 \%$ saline (PBS) and $0.1 \%$ sodium nitrite and heparin (1 $\mathrm{U} / \mathrm{ml}$ ). For studies involving $\mathrm{Cx} 30$ and $\mathrm{Cx} 43$, rats were perfused with 400 $\mathrm{ml}$ of cold $4 \%$ formaldehyde in $\mathrm{PB}$, followed by postfixation of brains for $2 \mathrm{hr}$ in the same fixative. Tissues were stored at $4^{\circ} \mathrm{C}$ for $24-48 \mathrm{hr}$ in cryoprotectant consisting of $50 \mathrm{~mm}$ PB containing $10 \%$ sucrose. For studies involving $\mathrm{Cx} 43$ and $\mathrm{Cx} 32$, rats were perfused with prefixative as above and then with $400 \mathrm{ml}$ of cold $4 \%$ formaldehyde in PB, followed by perfusion with $300 \mathrm{ml}$ of $0.1 \mathrm{M} \mathrm{PB}$ containing $10 \%$ sucrose. Brains were stored in cryoprotectant as above.

Cryostat sections (15 $\mu \mathrm{m}$ thick) were collected on gelatinized glass slides. For $\mathrm{Cx} 30 / \mathrm{Cx} 43$ double-immunofluorescence labeling, sections were incubated for $24 \mathrm{hr}$ at $4^{\circ} \mathrm{C}$ simultaneously with polyclonal rabbit anti-Cx43 (18A) diluted 1:1000 and monoclonal mouse anti-Cx30 diluted 1:500 in PBS containing 0.3\% Triton X-100 (PBST) and 2\% normal goat serum (NGS). For Cx43/Cx32 double-immunofluorescence labeling, sections were incubated for $24 \mathrm{hr}$ at $4^{\circ} \mathrm{C}$ simultaneously with polyclonal rabbit anti-Cx43 (18A) diluted 1:1000 and monoclonal mouse anti-Cx32 (7C7) diluted 1:25 in PBST containing 2\% NGS. After primary antibody incubations, sections were washed for $1 \mathrm{hr}$ in PBST and then incubated for $1.5 \mathrm{hr}$ at room temperature with indocarbocyanine (Cy3)-conjugated goat anti-mouse IgG (diluted 1:200 in PBST containing 2\% NGS) for labeling of either $\mathrm{Cx} 30$ or $\mathrm{Cx} 32$ or, simultaneously, with fluorescein isothiocyanate (FITC)-conjugated goat anti-rabbit IgG (diluted 1:50 in PBST containing $2 \%$ NGS) for labeling of $\mathrm{Cx} 43$. Sections were washed for $20 \mathrm{~min}$ in PBST and $20 \mathrm{~min}$ in $50 \mathrm{~mm}$ Tris- $\mathrm{HCl}$ buffer and coverslipped with anti-fade medium. Immunofluorescence double labeling for Cx32 and CNPase was conducted using monoclonal anti-Cx32 7C7 and a polyclonal anti-CNPase as described previously ( $\mathrm{Li}$ et al., 1997). In control procedures, omission of one or the other of the primary antibodies with inclusion of both of the secondary antibodies produced no inappropriate labeling (i.e., Cy3 labeling with rabbit primary or FITC labeling with monoclonal primary), indicating a lack of false-positive cross-reactions with the antibodies used. In addition, adsorption of the above anti-connexin antibodies with peptide antigen has been shown previously to eliminate all immunolabeling in tissue sections (Yamamoto et al., 1990b; Li et al., 1997; Nagy et al., 1999).

Fluorescence was examined on a Leitz Dialux 20 fluorescence microscope and an Olympus Fluoview confocal microscope. By the use of tissue sections singly labeled with either FITC- or Cy3-conjugated antibodies, confocal laser excitation intensity and photomultiplier tube detection of these labels were adjusted to produce minimal bleedover of the green fluorochrome into the red range. This was necessary because of the extended tail of long-wavelength emission of FITC, even with the use of appropriate $605-610 \mathrm{~nm}$ cutoff filters, as used here. Lack of bleedover was tested by scanning double-labeled sections twice using single laser excitation each time for one or the other fluorochrome.

Freeze-fracture. For FRIL immunocytochemistry, adult Sprague Dawley rats (11 males and 14 females; $128-585 \mathrm{gm})$ were anesthetized (ketamine, $90 \mathrm{mg} / \mathrm{kg}$; xylazine, $8 \mathrm{mg} / \mathrm{kg}$ ) and fixed for 3-10 min via transcardiac perfusion with $4,1,0.2$, or $0.1 \%$ formaldehyde in $150 \mathrm{~mm}$ Sorenson's phosphate buffer (SPB) as described previously (Hudson et al., 1981). Optimum cell preservation and labeling for connexins were obtained after fixation with $1 \%$ formaldehyde, and all images are from that procedure (for exceptions, see Figs. 5, 7F, which were from tissues fixed with $0.1 \%$ formaldehyde). All experiments were conducted according to the Principles of Laboratory Animal Care (National Institutes of Health publication number 86-23; revised 1985). Samples of formaldehyde-fixed brain and spinal cord were cut into $150-\mu \mathrm{m}$-thick slices using a Lancer 1000 Vibratome, infiltrated with $30 \%$ glycerol, and frozen by contact with a $-195^{\circ} \mathrm{C}$ "copper mirror" (Phillips and Boyne, 1984). Samples were freeze fractured in a JEOL RFD 9010C freeze- fracture device, shadowed with 1-1.5 nm of $\mathrm{Pt} / \mathrm{C}$, and coated with 5-10 $\mathrm{nm}$ of carbon. Frozen samples were bonded to gold "index" grids using 1.5-2\% Lexan plastic (GE Plastics, Pittsfield, MA; available locally from plastic sheet-goods suppliers) dissolved in dichloroethane and photography-mapped using a Molecular Dynamics MultiProbe 2001 inverted confocal microscope (Rash et al., 1995, 1997). Replicas were washed in $2.5 \%$ SDS detergent for $24-29 \mathrm{hr}$ with constant stirring, which leaves a thin film of membrane macromolecules adsorbed to the replica and available for immunogold labeling (Fujimoto, 1995; as modified in Rash and Yasumura, 1999).

Blocking nonspecific binding sites; immunogold labeling. Samples were immersed for $1-1.5 \mathrm{hr}$ at $22-24^{\circ} \mathrm{C}$ in primary antibody solution $(1 \mathrm{mg} / \mathrm{ml}$ stock solution of single antibodies or mixed primary antibodies from two or three species) mixed 1:100 with labeling blocking buffer (Rash et al., 1999), which consists of 0.15 M SPB plus $10 \%$ heat-inactivated goat serum and $0.5 \%$ teleost gelatin (Sigma). Two anti-Cx30, seven anti-Cx32, two anti-Cx36, and three anti-Cx43 antibodies were used, details of which are given in Tables 1 and 2. In some double- and triple-labeling experiments, the identity of astrocyte processes was confirmed by labeling the square array markers of astrocytes (AQP4 arrays) with anti-AQP4 antibodies (Rash et al., 1998b; Rash and Yasumura, 1999). Replicas were labeled for 1.5 or $12 \mathrm{hr}$ with species-specific secondary antibodies (goat anti-mouse, goat anti-rabbit, and donkey anti-sheep) coupled to $10 \mathrm{~nm}, 20 \mathrm{~nm}$, or 30-40 nm gold (Chemicon, Temecula, CA; now available directly from Jackson ImmunoResearch, West Grove, PA, and NanoProbes, Stony Brook, NY).

Electron microscopy. Labeled replicas were rinsed and air dried, and a second reinforcing carbon coat was applied on the labeled "tissue side" of the replica. The second carbon coat prevented displacement of the replica and of the gold labels during subsequent removal of the Lexan support film (Rash et al., 1995; Rash and Yasumura, 1999). The Lexan support film was removed by immersing the grid in six exchanges of dichloroethane for a total of 1-1.5 hr. Grids were air dried and examined at $100 \mathrm{kV}$ using a JEOL 2000 EX-II TEM. Overall, 303 labeled replicas were examined (Table 2) and photographed as stereoscopic pairs, with an $8^{\circ}$ included angle between images. Most images were printed at low and high magnification to allow assessment of the level of background immunogold labeling, which is always present with any particulate (i.e., immunogold) labeling procedure, even if not specified. When nonspecific labeling is high, discriminating signal from background is difficult, if not impossible. Consequently, the amount of clumping and of nonspecific labeling, as well as the "signal-to-noise ratio" (Rash and Yasumura, 1999), were determined for each replica that was used for quantitative analysis. Gold beads closer than $30 \mathrm{~nm}$ apart were considered to repre-

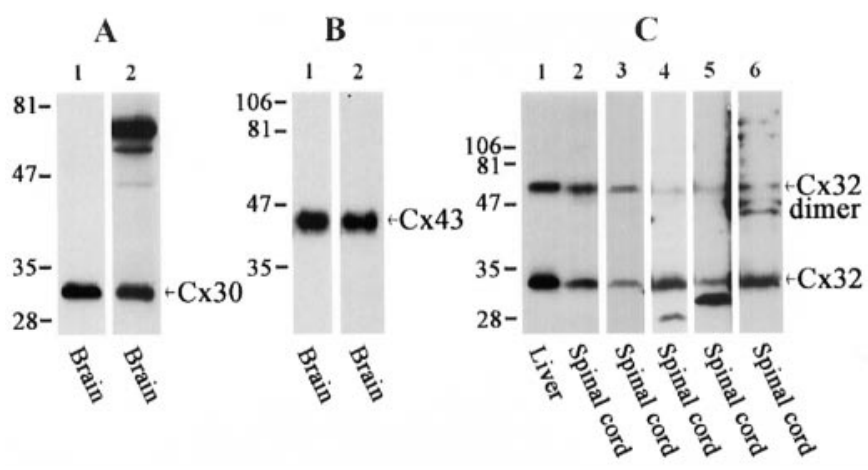

Figure 1. Western blots showing connexin detection in the CNS with the various anti-connexin antibodies used for LM immunofluorescence and FRIL. A, Blots of whole-brain homogenate probed with polyclonal (lane 1) and monoclonal (lane 2) anti-Cx30 antibodies. The top two intense bands detected by the monoclonal antibody may correspond to $\mathrm{Cx} 30$ dimer and trimer forms. $B$, Blots of whole-brain homogenate probed with polyclonal (lane 1) and monoclonal (lane 2) anti-Cx43 antibodies. C, Blots of liver and spinal cord homogenates probed with anti-Cx32 antibodies. Lanes 1, 2, Monoclonal 7C7; lane 3, Zymed monoclonal 2C2; lane 4, Sigma polyclonal; lane 5, Chemicon polyclonal; lane 6, Zymed polyclonal. Each of the antibodies detects the monomer form of $\mathrm{Cx} 32$ and to varying degrees its dimer form. The Sigma and Chemicon antibodies detect a lower molecular weight band of uncertain identity. Numbers on the left of each blot correspond to molecular weight markers. 

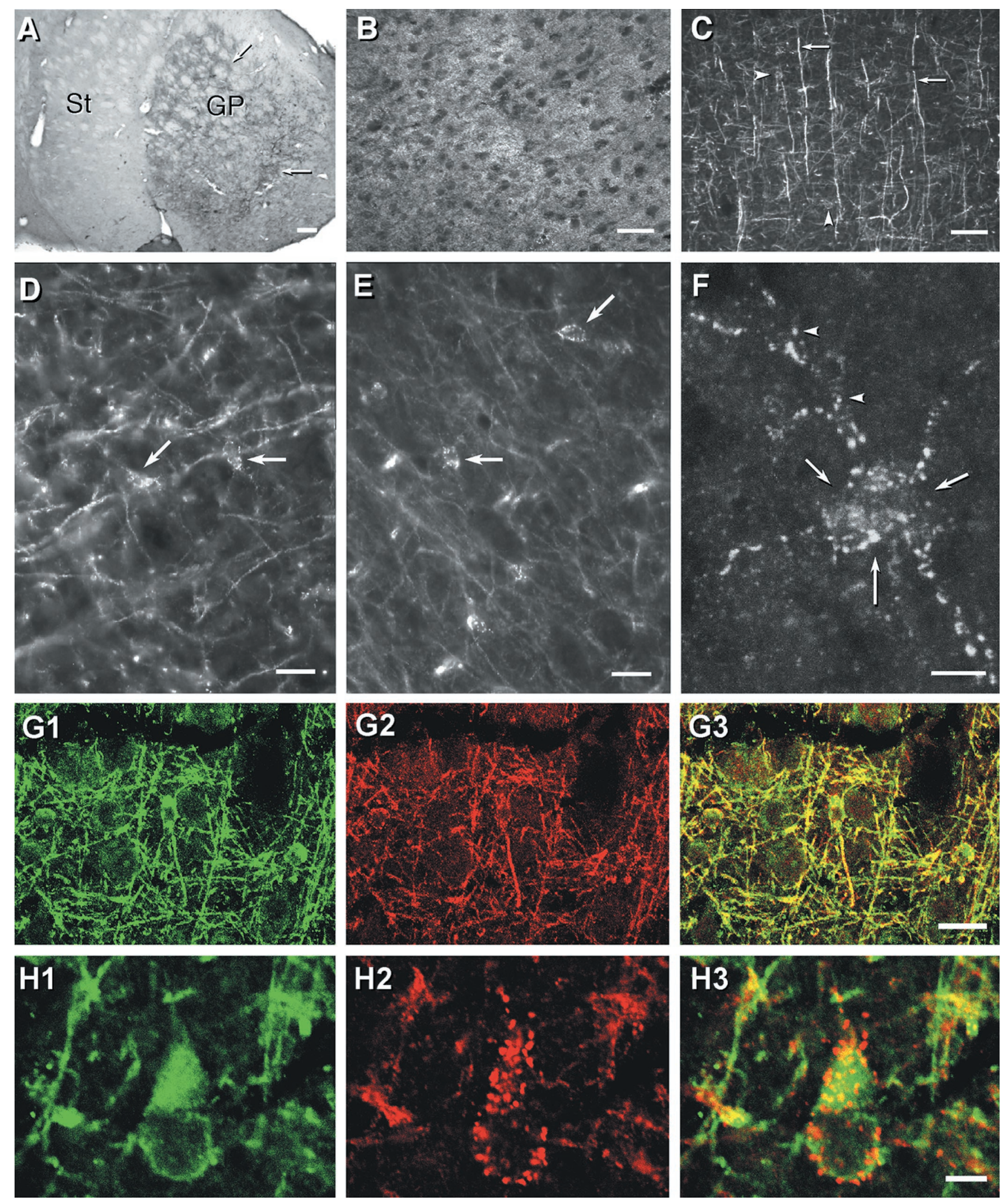

Figure 2. Photomicrographs showing patterns of immunolabeling obtained with various anti-connexin antibodies used in double-immunofluorescence and FRIL studies. $A$, Low magnification of immunoperoxidase labeling (arrows) with a monoclonal anti-Cx30 antibody. The section shows dense punctate labeling in the globus pallidus $(G P)$ and weaker labeling in the striatum $(S t)$. B, Cerebral cortex showing a high concentration of punctate immunofluorescence with anti-Cx43 antibody 18A. Dark ovals represent unstained neuronal cell bodies. C, Cx32 labeling of myelinated fibers (arrows) as well as oligodendrocyte cell bodies (arrowheads; cells barely discernable at this magnification) using antibody 7C7. D, E, Higher magnifications showing Cx32-positive puncta with antibody 7C7 along the surface of oligodendrocytes in the cerebral cortex (D; arrows) (Figure legend continues.) 
sent a single label. Omission of primary or secondary antibody resulted in the absence of labeling for that connexin (negative control). Many samples were examined and photographed "blind" with respect to each antibody label. Approximately half of the replicas were examined only briefly because of high background (potentially producing falsepositive labeling), failure of secondary labels (yielding false negatives), clumping of labels, or other artifacts of labeling (Rash and Yasumura, 1999). The total area per replica occupied by oligodendrocyte and neuronal gap junctions was small $\left(<1 \mu \mathrm{m}^{2}\right.$ of gap junction per 100,000 $\mu \mathrm{m}^{2}$ of replica surface), and the nonspecific background was $<1$ gold bead $/ \mu \mathrm{m}^{2}$. Consequently, the likelihood of finding nonspecific gold beads at gap junctions of oligodendrocytes and neurons was low, and false-positive labeling was a negligible factor in the analysis of cell coupling partners by FRIL. Furthermore, $>90 \%$ of nonspecific labels were on the Lexan (nontissue) side of the replica, allowing most nonspecific labeling to be distinguished from specific labeling (for rationale, see Rash and Yasumura, 1999). Stereoscopic images are presented to allow confirmation that all specific immunogold labeling was on the cytoplasmic side of the replicated gap junctions. (Stereoscopic images should be viewed with a conventional prop-up or stereopticon-type viewer.) In contrast, several samples were found to have no labeling of known connexin components in any gap junctions of the appropriate cell type (false-negative labeling). False-negative labeling was usually traced to bad lots of primary or secondary antibodies, and those replicas were either discarded (single labels), or if two or three labels were used, data were obtained only for the other labels (i.e., each label was evaluated independently of any other label that might be present). For FRIL, each lot of primary and secondary antibodies was tested and discarded when it had exceeded its useful shelf life $\left(<6\right.$ months at $4^{\circ} \mathrm{C}$ for both primary and secondary antibodies). Primary and secondary antibodies were not refrozen because each freeze-thaw cycle resulted in increased clumping of immunogold beads.

For the series of replicas used for quantitative FRIL analysis of oligodendrocyte coupling partners, oligodendrocyte extraplasmic leaflets were examined at high magnification for the presence of gap junctions. Counting of labeled versus unlabeled gap junctions was performed on oligodendrocyte coupling partners in the suprachiasmatic nucleus, hippocampus, and spinal cord. Nonquantified but directly supporting data were also obtained from gray matter areas of the paraventricular nucleus, cerebellum, and supraoptic nucleus. For quantification of Cx36-labeled neuronal gap junctions, samples of retina, inferior olive, and spinal cord were examined. To minimize bias in data collection and interpretation in samples used for quantitative analysis of cell coupling partners, every oligodendrocytic or neuronal membrane with either labeled or unlabeled gap junctions was photographed. No attempt was made to quantify connexin proteins; only the number of gap junction plaques containing gold labels for each connexin type was determined. In replicas used for quantitative analysis of cell coupling partners, the signal-to-noise ratio [defined as the density of gold beads per unit area of gap junction divided by the density of gold beads on nonjunctional areas of the same replica (Rash and Yasumura, 1999)] varied from 500:1 to 5000:1. In most samples, the labeling efficiency was $\geq 1$ gold bead per 30 connexons, which is sufficient to result in multiple gold beads (as many as 150) on all except the smallest gap junctions. In optimum conditions, each gold bead acts as an independently targeted label. Thus, multiple gold beads on an individual gap junction provide multiple independent confirmations of the presence of the target connexin within that specific gap junction plaque. In addition, consistent labeling for the same connexin in multiple gap junctions on multiple cells of a single cell type provides additional confidence of labeling efficacy and precludes "falsepositive" assignment to inappropriate cells or inappropriate membrane appositions. For each of the four connexins tested, this level of labeling was sufficient to label $>90 \%$ of gap junctions in each cell type and to label $>98 \%$ of gap junctions containing $>150$ connexons. In most cases, cell-specific ultrastructural markers and immunocytochemical labeling were used to confirm cell identifications (Rash et al., 1997).

\section{RESULTS \\ Western blotting}

Western blot analyses of nine of the anti-connexin antibodies used in the present study are shown in Figure 1. As reported previously in studies involving CNS tissues (Nagy et al., 1999), polyclonal anti-Cx30 antibody 71-2200 detected a single band migrating at $\sim 30 \mathrm{kDa}$ (Fig. $1 A$, lane 1 ), and monoclonal antiCx30 detected a similar band corresponding to $\mathrm{Cx} 30$ (Fig. $1 A$, lane 2). The monoclonal antibody also detected higher molecular weight bands that may correspond to multimeric forms of Cx30. The extensively used polyclonal anti-Cx43 antibody $18 \mathrm{~A}$ recognized $\mathrm{Cx} 43$ migrating at $\sim 43 \mathrm{kDa}$ (Fig. $1 B$, lane 1 ), and the commercially available monoclonal anti-Cx43 used here reacted with a corresponding protein (Fig. 1B, lane 2). The anti-Cx32 antibody 7C7 detected $\mathrm{Cx} 32$ monomer as well as its higher molecular weight dimer form in homogenates of liver and spinal cord (Fig. 1C, lanes 1, 2, respectively). Corresponding bands were revealed by each of the other anti-Cx32 antibodies tested in homogenates of spinal cord (Fig. 1C, lanes 3-6). Additional lower molecular weight proteins of unknown identity were detected by two of the commercially available anti-Cx32 antibodies (Fig. 1C, lanes 4, 5).

\section{LM immunohistochemistry}

The general appearance of immunolabeling produced with antiCx30, anti-Cx43, and anti-Cx32 antibodies at low and medium magnification of brain sections is shown in Figure 2. Results with monoclonal anti-Cx30 were qualitatively similar to those reported previously using a polyclonal antibody against Cx30 (Nagy et al., 1999). Labeling for Cx30 was detected throughout the brain, but its distribution was highly heterogenous in gray matter, and it was not detectable in white matter tracts. For example, in a representative section through portions of the basal ganglia, punctate immunoperoxidase staining for $\mathrm{Cx} 30$ was very dense in the globus pallidus and moderate to weak in the striatum (Fig. $2 A$ ), presumably reflecting differences in the number of astrocytes and/or astrocytic gap junctions in those areas.

Characteristic immunofluorescence-labeling patterns obtained with anti-Cx43 and anti-Cx32 antibodies are shown at low magnification in images from cerebral cortex labeled with antibody 18A (Fig. 2B) and 7C7 (Fig. 2C), respectively. Labeling for Cx43 was dense, widely distributed in both gray and white matter, and exclusively punctate, whereas labeling for Cx32 was seen along myelinated fibers and around numerous cells that were identified as oligodendrocytes on the basis of double labeling for Cx32 in combination with oligodendrocyte ultrastructural and cytochemical markers (Li et al., 1997) (see images below). Although visualization of immunopositive oligodendrocyte somata was obscured at low magnification by labeled myelinated fibers (Fig. $2 C$ ), oligodendrocytes were evident in magnified images, in which

and ventral lateral nucleus of the thalamus $(E$; arrows). $F$, Through-focus confocal micrograph of Cx32-immunopositive puncta distributed on an oligodendrocyte soma (arrows) and its processes (arrowheads). G, Double immunofluorescence of the oligodendrocyte marker CNPase (G1, green) and Cx32 $(G 2, r e d)$ in the same field of cerebral cortex. CNPase-positive cells are also immunopositive for Cx32 as seen by the overlay of images (G3, yellow). $H$, Higher magnification double-immunofluorescence confocal micrographs showing a CNPase-positive oligodendrocyte in cerebral cortex ( $H 1$ ) decorated with numerous Cx32-immunopositive puncta (red puncta in $H 2$ and red and yellow puncta in the overlay of images in $H 3$ ). Scale bars: $A$, 200 $\mu \mathrm{m} ; B, C, 50 \mu \mathrm{m} ; D, E, G, 20 \mu \mathrm{m} ; F, H, 5 \mu \mathrm{m}$. 

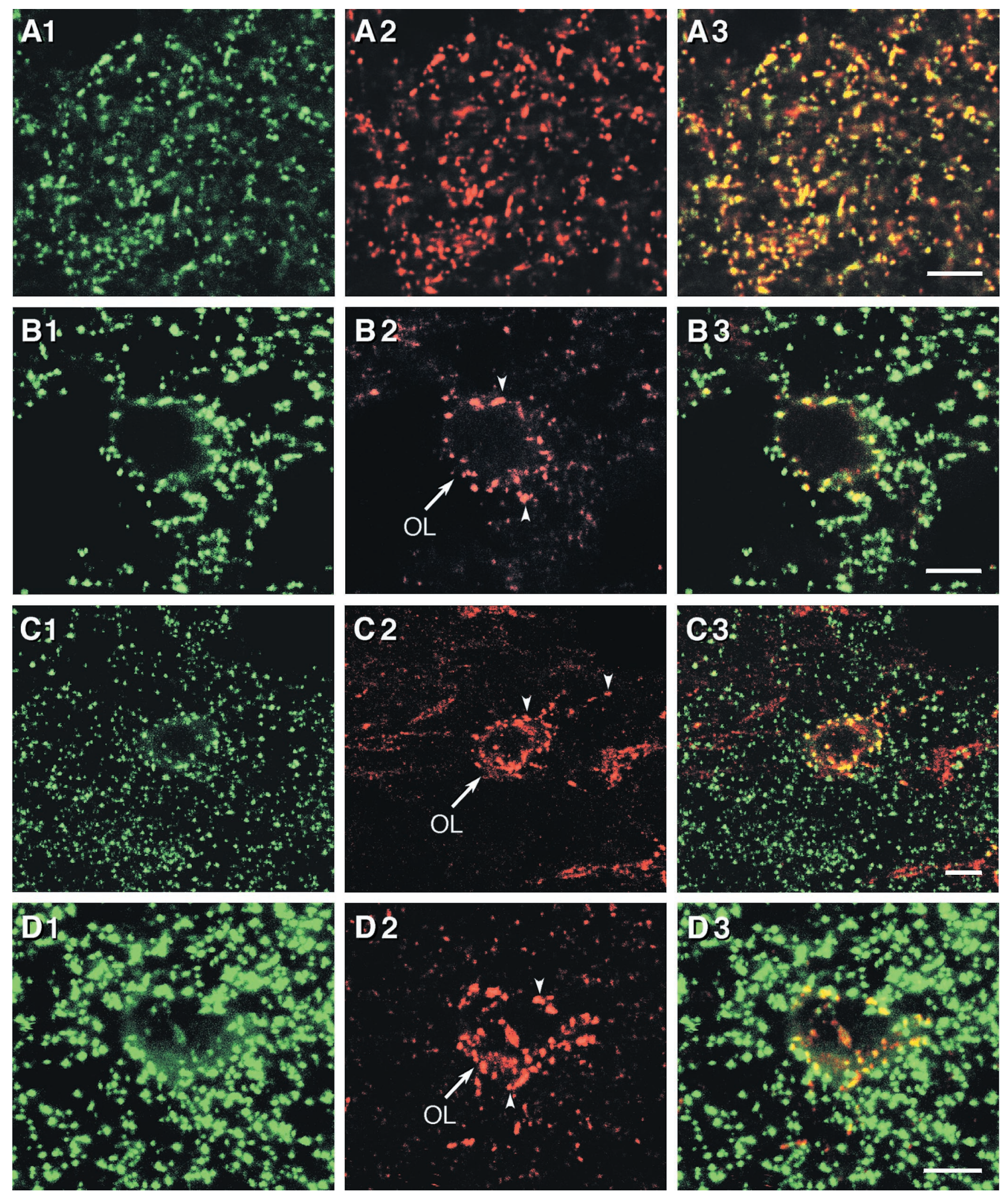

Figure 3. Confocal microscope images showing double-immunofluorescence labeling for connexins in various brain regions. $A 1-A 3$, Labeling for $\mathrm{Cx} 30$ (A1) and $\mathrm{Cx} 43$ (A2) in the subthalamic nucleus with the overlay (A3) showing colocalization in yellow. B-D, Labeling for Cx43 (green in B1, C1, D1) and Cx32 (red in B2,C2, D2) with the overlay showing colocalization (yellow in B3, C3, D3) of immunofluorescent puncta surrounding an oligodendrocyte $(O L$, arrow $)$ in the cerebral cortex $(B)$, the ventral lateral thalamic nucleus $(C)$, and the lateral hypothalamus $(D)$. Scale bars, $5 \mu \mathrm{m}$. 


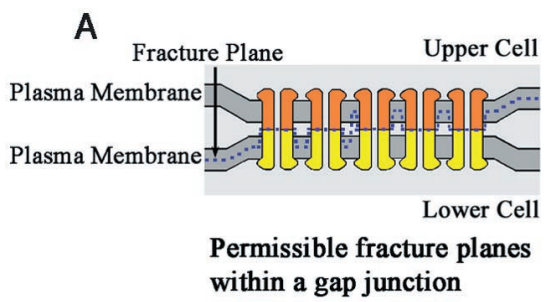

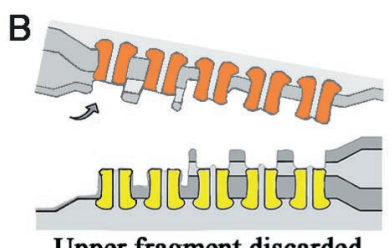

Upper fragment discarded
C

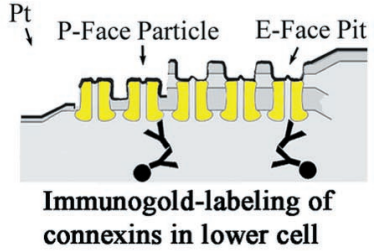

$\mathrm{F}$

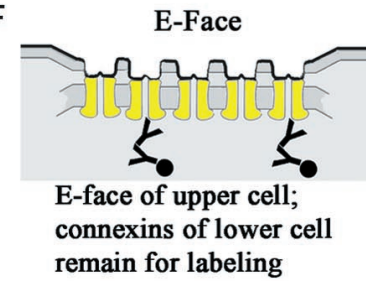

Figure 4. Diagrammatic representation of FRIL showing relationships between visualized freeze-fracture faces and the location of immunogoldlabeled connexins. A, A gap junction between two cells is shown where the fracture plane (blue dashed line) skips from the membrane bilayer of one cell to that of the other cell but always separates apposed connexons at the point of contact in the extracellular space. $B, C$, Where the membrane of the upper cell is fractured, the external leaflet (E-face) remains attached to the tissue fragment that contains the lower cell. The E-face pits delineate the sites from which the connexons were removed. Curved arrow indicates separation and removal of upper fragment. Pt arrow indicates direction of platinum shadowing. $D-F$, Where the fracture plane splits the membrane of the lower cell, the external leaflet is removed, exposing connexons as intramembrane particles in the protoplasmic leaflet (P-face). In all cases, regardless of whether the E-face of the upper cell or the P-face of the lower cell is replicated, only the connexons of the lower cell remain for potential labeling by FRIL.

\begin{tabular}{|c|c|c|c|c|}
\hline \multirow[b]{2}{*}{ Connexin } & \multicolumn{3}{|c|}{$\begin{array}{l}\text { Number of labeled junctions in membranes of each } \\
\text { cell type }\end{array}$} & \multirow{2}{*}{$\begin{array}{l}\text { Coupling relationships } \\
\text { (cell pairings) }\end{array}$} \\
\hline & Astrocyte & Oligodendrocyte & Neuron & \\
\hline $\mathrm{Cx} 32$ & 0 & 83 & 0 & $\mathrm{O}$ side of $\mathrm{O}-\mathrm{A}^{\mathrm{a}}$ \\
\hline \multirow[t]{2}{*}{$\mathrm{Cx} 30$} & 189 & 0 & 0 & $\mathrm{~A}-\mathrm{A}$ \\
\hline & $25^{\mathrm{b}}$ & 0 & 0 & A side of $\mathrm{O}-\mathrm{A}$ \\
\hline \multirow[t]{2}{*}{$\mathrm{Cx} 43$} & $>3000$ & 0 & 0 & $\mathrm{~A}-\mathrm{A}$ \\
\hline & $>200^{\mathrm{b}}$ & 0 & 0 & A side of $\mathrm{O}-\mathrm{A}$ \\
\hline $\mathrm{Cx} 36$ & 0 & 0 & 259 & $\mathrm{~N}-\mathrm{N}$ \\
\hline
\end{tabular}

${ }^{\mathrm{a}} \mathrm{A}$, Astrocyte; N, neuron; O, oligodendrocyte

${ }^{b}$ Includes data from the 169 gap junctions labeled for $\mathrm{Cx} 30$ and $\mathrm{Cx} 43$ that were used for semiquantitative analysis of oligodendrocyte coupling partners.

their cell bodies and initial processes were delineated by punctate immunofluorescence, as shown by conventional LM of cerebral cortex (Fig. 2D) and the ventral lateral nucleus of the thalamus (Fig. 2E). By high-magnification through-focus confocal microscopy of a single oligodendrocyte in the hippocampus (Fig. $2 F$ ), $>60$ puncta were present on the oligodendrocyte cell body and proximal processes. Confirmation that these puncta were associated with oligodendrocytes was obtained in numerous brain areas double-labeled for $\mathrm{Cx} 32$ and an oligodendrocyte-specific marker, CNPase. Examples are shown by standard fluorescence (Fig. 2G) and confocal (Fig. 2H) microscopy in areas of cerebral cortex. CNPase was localized to oligodendrocyte somata and their myelinating processes along axons (Fig. 2G1), both of which also were immunopositive for $\mathrm{Cx} 32$ (Fig. 2G2,G3). Within this meshwork of labeling, CNPase-positive oligodendrocyte cell bodies, and occasionally their initial processes, were consistently outlined by numerous Cx32-immunopositive puncta (Fig. $2 G 2, G 3)$. Where CNPase was not present, labeling for $\mathrm{Cx} 32$ was not detected, suggesting that $\mathrm{Cx} 32$ is present only in oligodendrocytes.
Double immunofluorescence for glial connexins, as visualized by confocal microscope scans of $1-3 \mu \mathrm{m}$ optical slices of tissue, is shown in Figure 3. In sections double-labeled for $\mathrm{Cx} 43$ and $\mathrm{Cx} 30$, correspondence of punctate immunofluorescence in gray matter was high in each of several brain regions examined. This was exemplified in images of the subthalamic nucleus in which dense punctate staining for $\mathrm{Cx} 43$ (Fig. 3A2) and Cx30 (Fig. 3A1) was often closely associated (Fig. 3A3). (We use "close association" rather than "colocalization" because the resolution of confocal microscopy cannot distinguish between structures separated by $<0.3 \mu \mathrm{m}$.) In these double-labeled sections, $\mathrm{Cx} 43$ was evident in white matter, whereas no labeling for $\mathrm{Cx} 30$ was detected in white matter tracts, such as the corpus callosum, anterior commissure, and internal capsule. In sections labeled for both $\mathrm{Cx} 43$ and $\mathrm{Cx} 32$, a small proportion of $\mathrm{Cx} 43$-immunopositive puncta in gray as well as white matter was associated with oligodendrocyte cell bodies. Among the numerous Cx43-positive puncta (Fig. 3B1,C1,D1, green immunofluorescence), a small fraction were closely associated with Cx32-positive puncta (Fig. 3B2,C2,D2, red immunofluorescence), which delineated oligodendrocyte cell bodies. This 

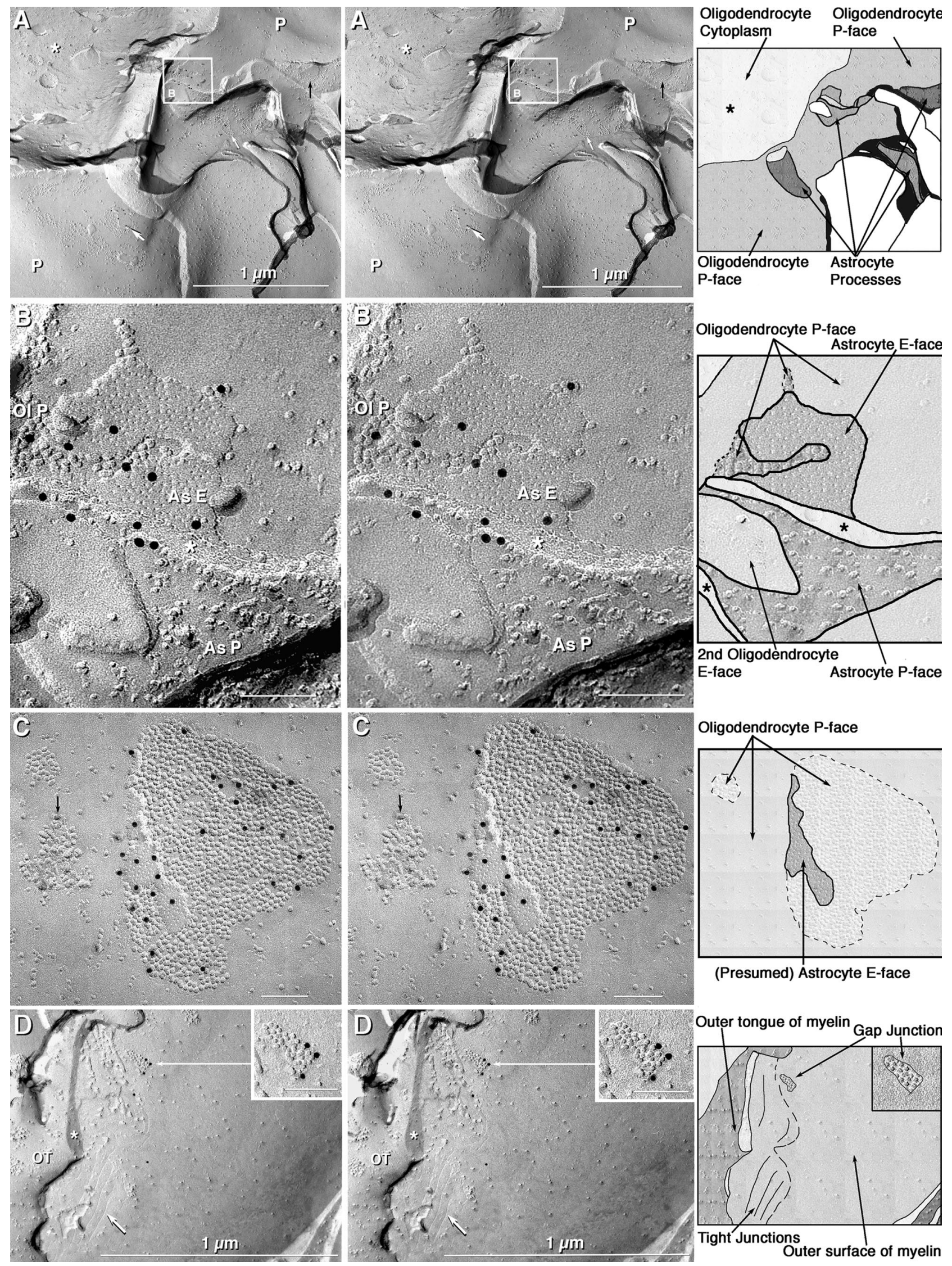

(Presumed) Astrocyte E-face

Outer tongue of myelin Gap Junction

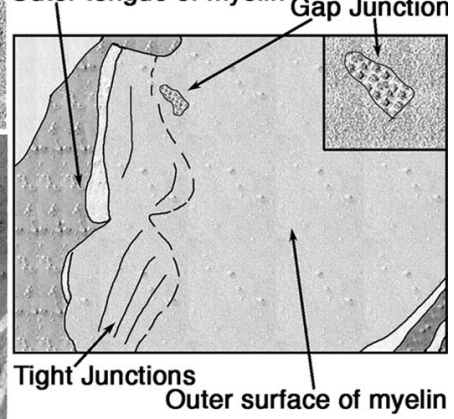

Figure 5. Stereoscopic images of Cx32 labeling of gap junctions in oligodendrocyte plasma membranes in the cerebellum, with explanatory diagrams. $A$, Oligodendrocyte cell body with a broad expanse of plasma membrane P-face $(P)$ enclosing the cross-fractured cytoplasm (asterisk). Arrows point to two Cx32-labeled gap junctions in the oligodendrocyte P-face (white arrows) and one unlabeled gap junction in the nearby astrocyte (Figure legend continues.) 
close association of $\mathrm{Cx} 43$ and $\mathrm{Cx} 32$ (double immunofluorescence appearing yellow) is evident in overlays of corresponding images taken in regions of cerebral cortex (Fig. 3B3), the ventral nucleus of the thalamus (Fig. 3C3), and the lateral hypothalamus (Fig. 3D3). Close association of Cx32 and $\mathrm{Cx} 43$ was evident at hundreds of oligodendrocytes that were examined in dozens of brain regions in sections derived from several animals. Overall, however, Cx43-immunopositive puncta greatly outnumbered $(>100: 1)$ the Cx32- plus Cx43 doublelabeled puncta surrounding individual oligodendrocytes. A basis for the close association of $\mathrm{Cx} 32$ and $\mathrm{Cx} 43$ puncta was ascertained by FRIL (below).

\section{Freeze-fracture immunogold labeling}

FRIL provides for immunocytochemical identification of membrane proteins and subcellular localization to distinct ultrastructural features, such as gap junctions (Fig. 4). In FRIL, the fracture plane may split either of the apposed membranes or sequentially split both apposed membranes, revealing the protoplasmic leaflet (P-face) of the lower cell, composite P-face and extraplasmic leaflet (E-face) images derived from portions of both cells (Fig. 4B,E), or only the E-face of the upper cell (Fig. $4 F$ ). Although membranes are split, the fracture plane does not break covalent bonds within transmembrane proteins but, instead, separates the apposed connexons at the point of apposition in the extracellular space. Thus, in vertebrates, each gap junction is cleanly separated into two plaques of hemichannels, with each plaque containing connexins derived from only one cell (Fig. 4, orange vs yellow connexons). In P-faces, connexons are replicated as distinctive arrays of intramembrane particles (IMPs). The removal of connexons by cleaving leaves equally distinctive arrays of impressions or "pits" in the E-face, which is devoid of connexin proteins. However, every gap junction E-face overlies the unsplit gap junctional membrane of the lower cell, which contains the connexons and connexin proteins of the lower cell (Fig. 4C,F). Thus, whether the fracture plane exposes the E-face of the upper cell, exposes the P-face of the lower cell, or repeatedly steps from E- face to $\mathrm{P}$-face within a gap junction, it is only the connexons of the lower cell that remain for immunogold labeling (Fig. $4 C-F$, yellow connexons). Moreover, no contaminating connexins from the upper cell remain in the replicated E-face and, thus, cannot cause false-positive FRIL labeling of connexins in the lower cell. [This report does not illustrate labeling of crossfractured gap junctions or areas where the cleaving plane exits the membrane and enters the cytoplasm of the upper cell. Those sources of "cryptic labeling" are described in Rash and Yasumura (1999).] Consequently, in addition to its ability to identify connexins in gap junction P-faces (Fig. 4D), a unique advantage of FRIL in this investigation is its ability to allow visualization and positive structural identification of the exter- nal leaflet (E-face) of one cell while revealing the connexin composition of the attached cellular coupling partner (Fig. $4 E$ ). Thus, for classes of connexins that are restricted to a specific cell type (as documented below), FRIL provides a method to identify the lower cell that is based solely on its constituent connexins, even when little or none of the P-face or cytoplasm of the lower cell is visible in the replica (Fig. 4F). However, in most cases, portions of both cells were replicated, allowing other ultrastructural features to be used to confirm cell identifications. This cell-specific connexin labeling within individual gap junction plaques provides the basis for FRIL identification and quantitative analysis of oligodendrocyte and neuronal coupling partners. Whether or not additional connexins are found to be shared among glial cells and/or neurons, the cell-specific expression of these four connexins allows each to be used as a marker for identifying cellular coupling partners.

\section{Cx32 at oligodendrocyte gap junctions but not in oligodendrocyte coupling partners}

Oligodendrocytes were identified in freeze-fracture replicas according to established criteria, including the following: (1) characteristic low density of IMPs in both P- and E-faces, particularly in myelin (see Figs. $5 D, 7,9),(2)$ the presence of "reciprocal patches" of mixed IMPs and pits in both E- and P-faces (see Figs. 5, 8), and (3) noncrystalline packing of IMPs and pits in their gap junctions (see Figs. 5, 7-9) (Hatton and Ellisman, 1981; Landis, 1981; Massa and Mugnaini, 1982; Waxman and Black, 1984; Mugnaini, 1986; Rash et al., 1997). Likewise, astrocytes and neurons were identified on the basis of published criteria (Hatton and Ellisman, 1981; Landis, 1981; Mugnaini, 1986; Rash et al., 1996, 1997), as described below. In freeze-fracture replicas of spinal cord, hippocampus, suprachiasmatic nucleus, paraventricular nucleus, and cerebellum that were examined after single, double, or triple labeling for various combinations of Cx32 plus Cx30, Cx36, Cx43, and/or AQP4 (Table 2), as many as 41 intercellular gap junctions were observed on P-faces of individual oligodendrocyte somata, in this case, 35 of which were labeled for $\mathrm{Cx} 32$. In samples with high labeling efficiency, 83 of 98 gap junctions in oligodendrocyte P-faces were labeled for Cx32 (Table 3). Of these, 48 labeled gap junctions were in somatic plasma membranes and 35 were in myelin (see below). In several instances in which sufficient area was present to permit positive identification of both cells, all coupling partners overlying oligodendrocyte P-faces were identified as astrocytes, and the oligodendrocyte sides of these astrocyte-to-oligodendrocyte junctions were consistently labeled for $\mathrm{Cx} 32$ (Fig. 5B). Cx32-labeled oligodendrocyte gap junctions consisting of 9-1300 connexons were labeled by $1-31$ gold beads (range illustrated in Fig. $5 B-D$ ). This overall labeling efficiency of 1 gold per 30 connexons (1:30),

\section{$\leftarrow$}

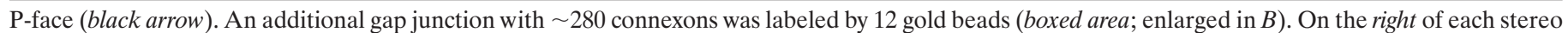

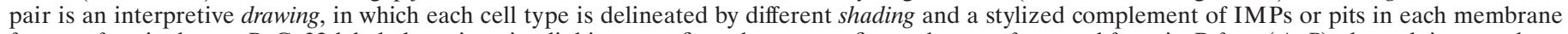

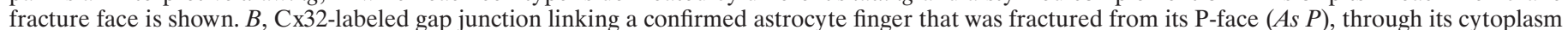

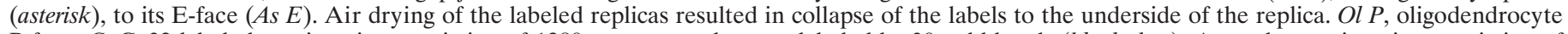

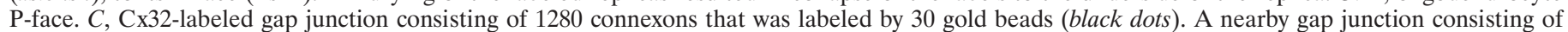

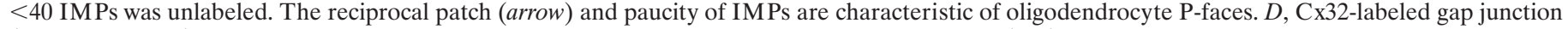

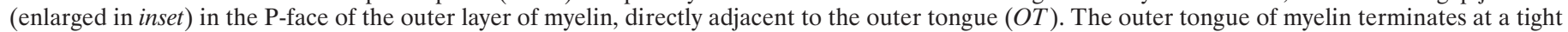

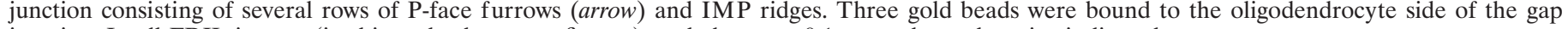
junction. In all FRIL images (in this and subsequent figures), scale bars are $0.1 \mu \mathrm{m}$ unless otherwise indicated. 
Figure 6. Stereoscopic images of astrocyte gap junctions in the suprachiasmatic nucleus after labeling for $\mathrm{Cx} 43$ and AQP4 $(A)$, in the supraoptic nucleus after labeling for $\mathrm{Cx} 30(B)$, in the supraoptic nucleus after double labeling for $\mathrm{Cx} 43$ and $\mathrm{Cx} 30(C)$, and in the paraventricular nucleus after triple labeling for $\mathrm{Cx} 30, \mathrm{Cx} 32$, and Cx43 (D). A, Two astrocyte-toastrocyte gap junctions labeled for Cx43 (20 nm beads; large arrows) beneath their E-faces $(E)$ and $\mathrm{P}$-faces $(P)$. Square arrays in P-faces were labeled for AQP4 (10 nm gold beads; small arrow and inset). $B$, Astrocyteto-astrocyte gap junction labeled for Cx30 (10 nm gold). $C$, A gap junction linking two astrocyte processes after double labeling for Cx30 (10 nm gold beads) and $\mathrm{Cx} 43$ (20 nm gold beads). Astrocytes were positively identified by the presence of AQP4 square arrays in both P-faces (white arrows) and E-faces (black arrows), as well as by the high density of IMPs on both Pand E-faces. $D$, Two astrocyte gap junctions triple-labeled for $\mathrm{Cx} 30$ (20 $\mathrm{nm}$ gold), Cx43 (30-40 nm gold), and Cx32 (10 nm gold; none present). Cx32 was not detected in astrocyte-toastrocyte gap junctions but was detected in astrocyte-to-oligodendrocyte gap junctions (Fig. 5).

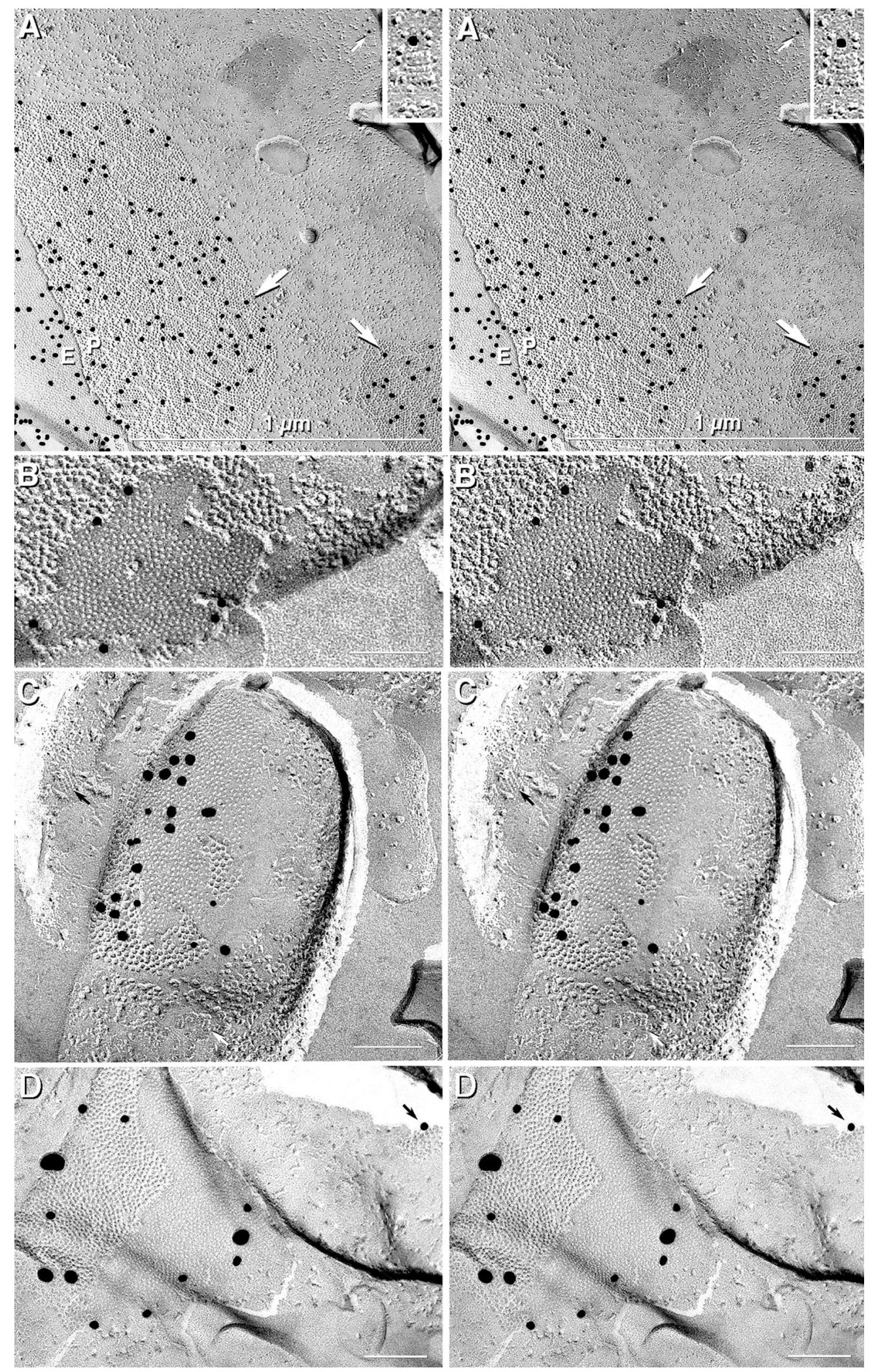

combined with low nonspecific background and high signal-tonoise ratio, resulted in multiple labeling of all except the smallest gap junctions (i.e., <30 connexons).

Oligodendrocyte gap junctions were also observed in the outermost layer of myelin, where only oligodendrocyte-to-astrocyte gap junctions have been documented (Waxman and Black, 1984;
Mugnaini, 1986; Rash et al., 1997, 1998b). Even in gap junctions having few connexons, the oligodendrocyte sides of intercellular gap junctions in the outer surface of myelin were consistently labeled for Cx32 (Fig. 5D). Overall, 35 of 44 intercellular gap junctions in the outermost, uncompacted layer of myelin were labeled for Cx32. [This study of cellular coupling partners did not 
address the composition or distribution of autologous or "reflexive" gap junctions linking layers deeper within myelin (Sandri et al., 1977; Scherer et al., 1995).] In contrast to gap junctions in oligodendrocyte P-faces, nearby astrocyte P-faces (Fig. 5A, black arrow) and neuronal $\mathrm{P}$ - and $\mathrm{E}$-faces were never labeled for $\mathrm{Cx} 32$. The absence of Cx32 in neurons is particularly noteworthy because in $\sim 80$ of the Cx32-labeled replicas of brain and spinal cord, extensive searches had been conducted using Cx32 immunogold as "flags" to aid in searches for proposed Cx32-containing neuronal gap junctions (Micevych and Abelson, 1991; Nadarajah et al., 1996; Alvarez-Maubecin et al., 2000). However, in tissues in which we had previously found $>100$ neuronal gap junctions (Rash et al., 1996, 2000), no Cx32-labeled neuronal gap junctions were found. Overall, Cx32 was detected by FRIL only in gap junction plaques of oligodendrocyte plasma membranes and never in astrocytes or neurons (Table 3).

Although gap junctions were consistently labeled for $\mathrm{Cx} 32$ in oligodendrocyte plasma membrane P-faces (Table 3), no connexins were labeled for $\mathrm{Cx} 32$ in the cells beneath oligodendrocyte gap junction E-faces (i.e., in oligodendrocyte coupling partners; Table 3; see Fig. 8C), suggesting that few if any oligodendrocytes share gap junctions with other oligodendrocytes. Moreover, the absence of Cx32 labeling in the gap junctions of oligodendrocyte coupling partners could not be explained by increased susceptibility to SDS detergent solubilization of oligodendrocyte connexins beneath E-faces because Cx32 labeling was frequently found in oligodendrocyte plasma membranes beneath astrocyte E-faces at confirmed astrocyte-to-oligodendrocyte gap junctions (Fig. $5 B$ ). Thus, the absence of $\mathrm{Cx} 32$ in oligodendrocyte coupling partners required that additional samples be examined by FRIL using antibodies to $\mathrm{Cx} 30, \mathrm{Cx} 43$, and $\mathrm{Cx} 36$, which are connexins expressed in the other cell types with which oligodendrocytes have been proposed to couple (Massa and Mugnaini, 1982; Mugnaini, 1986; Nadarajah et al., 1996; Rash et al., 1997; AlvarezMaubecin et al., 2000).

\section{Cx43 and Cx30 as definitive markers of astrocyte gap junctions}

To investigate Cx43 localization by FRIL, particularly with respect to oligodendrocyte coupling partners, 126 replicas of adult rat brain and spinal cord were single-, double-, or triple-labeled with antibodies to $\mathrm{Cx} 43$ plus various combinations of consensus neuronal and glial connexins (Cx30, Cx32, and Cx36), with some replicas also labeled for AQP4 to confirm astrocyte identities. In neuropil, $>1500 \mathrm{Cx} 43$-labeled gap junction P-faces were found, and these were always in astrocytes (Table 3; Fig. 6A) or in ependymocytes (Rash et al., 1998b; Rash and Yasumura, 1999). In addition, $>1500 \mathrm{Cx} 43$-labeled astrocyte gap junction E-faces were found, $>95 \%$ of which were between two astrocytes. (The remaining astrocyte coupling partners were oligodendrocytes; see below.) Confirmation that the cells forming these $\mathrm{Cx} 43$-labeled gap junctions were astrocytes was based on both ultrastructural and biochemical markers, including the following: (1) the presence of labeled or unlabeled AQP4 arrays in their plasma membranes (Fig. 6A,B; also see Fig. $5 B$ ), (2) a distinctively high density of IMPs in their plasma membrane E- and P-faces (Fig. $6 A, C$; also see Fig. $5 B$ ), and (3) clusters of GFAP filaments in their cross-fractured cytoplasms (see Fig. $8 A, B$ ). In one series of samples that had very low background and high signal-to-noise ratio, $\sim 90 \%$ of astrocyte gap junctions were labeled for $\mathrm{Cx} 43$, and the remaining $10 \%$ (mostly gap junctions with $<50$ connexons) were unlabeled. Moreover, Cx43 was not detected in the plasma membranes of any other cell type in gray or white matter. [FRIL analysis of ependymocyte gap junctions revealed that they also contain Cx43 (Rash et al., 1998a,b; Rash and Yasumura, 1999), but because ependymocytes are restricted to the linings of the brain ventricles and spinal cord central canal, they were excluded from this analysis of neuronal and glial coupling partners in neuropil and white matter.]

In samples labeled for Cx30 (see Figs. $6 B, 8 C$ ) or Cx30 plus Cx43 (see Figs. $6 C, D, 9 B$ ), $>200$ astrocyte gap junction plaques were found, $\sim 90 \%$ of which were labeled (Table 3 ). By alternately using large versus small gold beads targeted to $\mathrm{Cx} 43$ and $\mathrm{Cx} 30$, approximately equal amounts of $\mathrm{Cx} 30$ and $\mathrm{Cx} 43$ were detected in most of the larger astrocyte-to-astrocyte gap junctions (Fig. 7C). To test whether the high proportions of gap junctions that were separately labeled for $\mathrm{Cx} 43$ or Cx30 reflected an artifact of a selective search strategy (i.e., biased searching only for labeled gap junctions) or accurately reflected overlapping populations of gap junctions expressing two or more connexins, labeled and unlabeled gap junctions were quantified after simultaneous double labeling for $\mathrm{Cx} 30$ and $\mathrm{Cx} 43$ (with or without additional labeling for $\mathrm{Cx} 32$ or $\mathrm{Cx} 36$ ). Labels for both $\mathrm{Cx} 30$ and $\mathrm{Cx} 43$ were present in $\sim 80 \%$ of gap junctions in astrocyte plasma membranes (Fig. $6 B, C$ ). Nevertheless, $\sim 15 \%$ of small gap junctions were labeled for only one of the two connexins, and $\sim 5 \%$ were unlabeled (Figs. $8 A, 9 B$ ). In contrast, no gap junctions in either oligodendrocyte or neuronal P-faces were labeled by $\mathrm{Cx} 43$ or Cx30 (Table 3). Thus, of the connexins tested by FRIL, Cx30 and $\mathrm{Cx} 43$ were colocalized only in the gap junction plaques of astrocytes and thus are definitive FRIL markers of astrocytes and no other neural cells.

\section{Oligodendrocyte coupling partners have Cx30 and Cx43 in their plasma membranes}

In replicas that were single-, double-, or triple-labeled for $\mathrm{Cx} 30$ and $\mathrm{Cx} 43$ plus $\mathrm{Cx} 32$ or $\mathrm{Cx} 36$, the connexins beneath oligodendrocyte gap junction E-faces (i.e., connexins of the underlying oligodendrocyte cellular coupling partners) were consistently labeled for $\mathrm{Cx} 43$, Cx30, or Cx30 plus Cx43 (Figs. 7-9; Table 3). In a preliminary survey, eight oligodendrocyte cell bodies were observed containing 12 gap junctions in their E-faces, all of which were labeled for $\mathrm{Cx} 30$ and/or $\mathrm{Cx} 43$. Likewise, in eight myelinated processes, nine of nine oligodendrocyte gap junction E-faces were labeled for $\mathrm{Cx} 30$ and/or $\mathrm{Cx} 43$. In contrast, no oligodendrocyte intercelular gap junction E-faces were labeled for $\mathrm{Cx} 32$ or $\mathrm{Cx} 36$ (Fig. $7 F$ ). This suggested that $\mathrm{Cx} 32-$ containing oligodendrocytes share gap junctions with astrocytes containing both $\mathrm{Cx} 30$ and $\mathrm{Cx} 43$ but do not share gap junctions with other oligodendrocytes or with neurons. In other samples, as many as $27 \mathrm{Cx} 43$-labeled gap junctions were found in a single oligodendrocyte E-face, indicating that each oligodendrocyte is coupled to many astrocyte processes.

As an independent method for identifying and quantifying the relative numbers of oligodendrocyte-to-astrocyte, oligodendrocyteto-oligodendrocyte, and oligodendrocyte-to-neuron coupling pairs, a quantitative approach was used with a limited number of replicas having a high labeling efficiency, low background, and high signalto-noise ratio. To minimize investigator bias in this series of replicas, we photographed every observed oligodendrocyte E-face having one or more gap junctions, whether or not the gap junctions were immunogold labeled. From those quantitative gap junction data, the proportion of oligodendrocytes, astrocytes, and neurons as oligodendrocyte coupling partners was determined. Plasma 
Figure 7. Stereoscopic images of paired oligodendrocytes linked by tight junctions in the suprachiasmatic nucleus $(A-E)$ after labeling for $\mathrm{Cx} 43$ and AQP4 and in the inferior olive $(F)$ after double labeling for $\mathrm{Cx} 43$ (10 nm gold) and $\mathrm{Cx} 36$ (20 nm gold; none present in any oligodendrocyte gap junction). $A$, Low-magnification image of the large expanse of oligodendrocyte concave plasma membrane E-face contacting the cell body of a second oligodendrocyte, which has cross-fractured cytoplasm (asterisk). Boxes delineate areas of tight junctions $(B)$ and 2 of the $12 \mathrm{Cx} 43$ labeled gap junctions seen in this oligodendrocyte E-face $(C)$. $B$, Higher magnification image of the region linked by tight junctions. No gap junctions were within the sealed compartments enclosed by tight junction strands, but gap junctions were numerous in the nearby plasma membrane. $C$, Higher magnification image of two $\mathrm{Cx} 43$-labeled gap junctions whose connexons were in the plasma membrane of the oligodendrocyte coupling partner (boxed areas $D, E$, shown at higher magnification). $D, E$, Gap junctions labeled for $\mathrm{Cx} 43$ by 10 nm gold. "Reciprocal patches" of IMPs (arrows) were present in the margins of both gap junctions. Cx36 labeling (20 $\mathrm{nm}$ gold) was not present in any oligodendrocyte coupling partner. $F$, Tight junction strands linking two oligodendrocytes, with nearby gap junctions in the oligodendrocyte coupling partner labeled for $\mathrm{Cx} 43$.
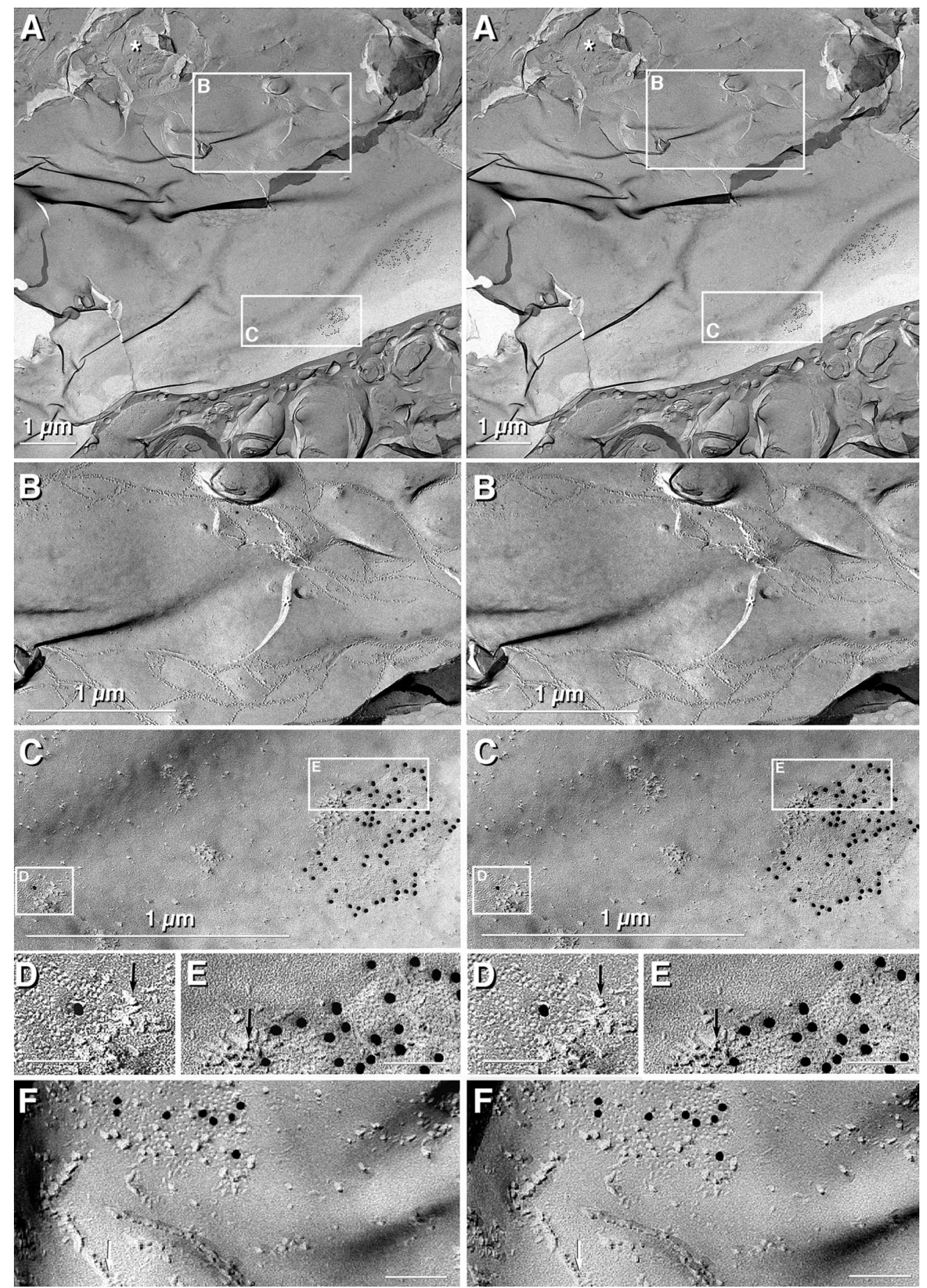

membrane E-faces of 57 oligodendrocytes containing a total of 169 gap junctions were found. Of these $169,89 \%$ were labeled for $\mathrm{Cx} 43$ (Figs. $7 A, C, D, 8 A, B, 9 A$ ), Cx30 (Fig. $8 C$ ), or $\mathrm{Cx} 43$ plus $\mathrm{Cx} 30$ (Figs. $6 B, C, 9 B)$, thereby identifying those oligodendrocyte coupling partners as astrocytes. In most of those examples, the identification of Cx43-labeled oligodendrocyte coupling partners as astrocytes was confirmed on the basis of the presence of labeled or unlabeled AQP4 arrays in their plasma membranes (Fig. 8A) or of GFAP filaments in their cytoplasms (Fig. 8B). Included in the 169 gap junctions are data from 19 myelinated processes in which 34 gap junctions were observed in the outermost layer of myelin. Twentynine $(85 \%)$ of these were labeled for $\mathrm{Cx} 43, \mathrm{Cx} 30$, or $\mathrm{Cx} 43$ plus
Cx30 (Fig. 9), identifying those as oligodendrocyte myelin-toastrocyte junctions.

An additional $8 \%$ of the 169 gap junctions in oligodendrocyte E-faces were not labeled for either $\mathrm{Cx} 43$ or $\mathrm{Cx} 30$ but were identified as oligodendrocyte-to-astrocyte on the basis of ultrastructural or immunocytochemical markers. Occasionally both labeled and unlabeled gap junctions were in close proximity (Figs. $8 A, B, 9 B$, junctions 2,3$)$. Most of the remaining coupling partners at unlabeled gap junctions were positively identified as astrocytes, either because the unlabeled gap junction was one of two gap junctions coupled to the same cell process, with the second gap junction labeled for astrocytic $\mathrm{Cx} 43$ or $\mathrm{Cx} 30$ (Fig. $8 A$ ), because 

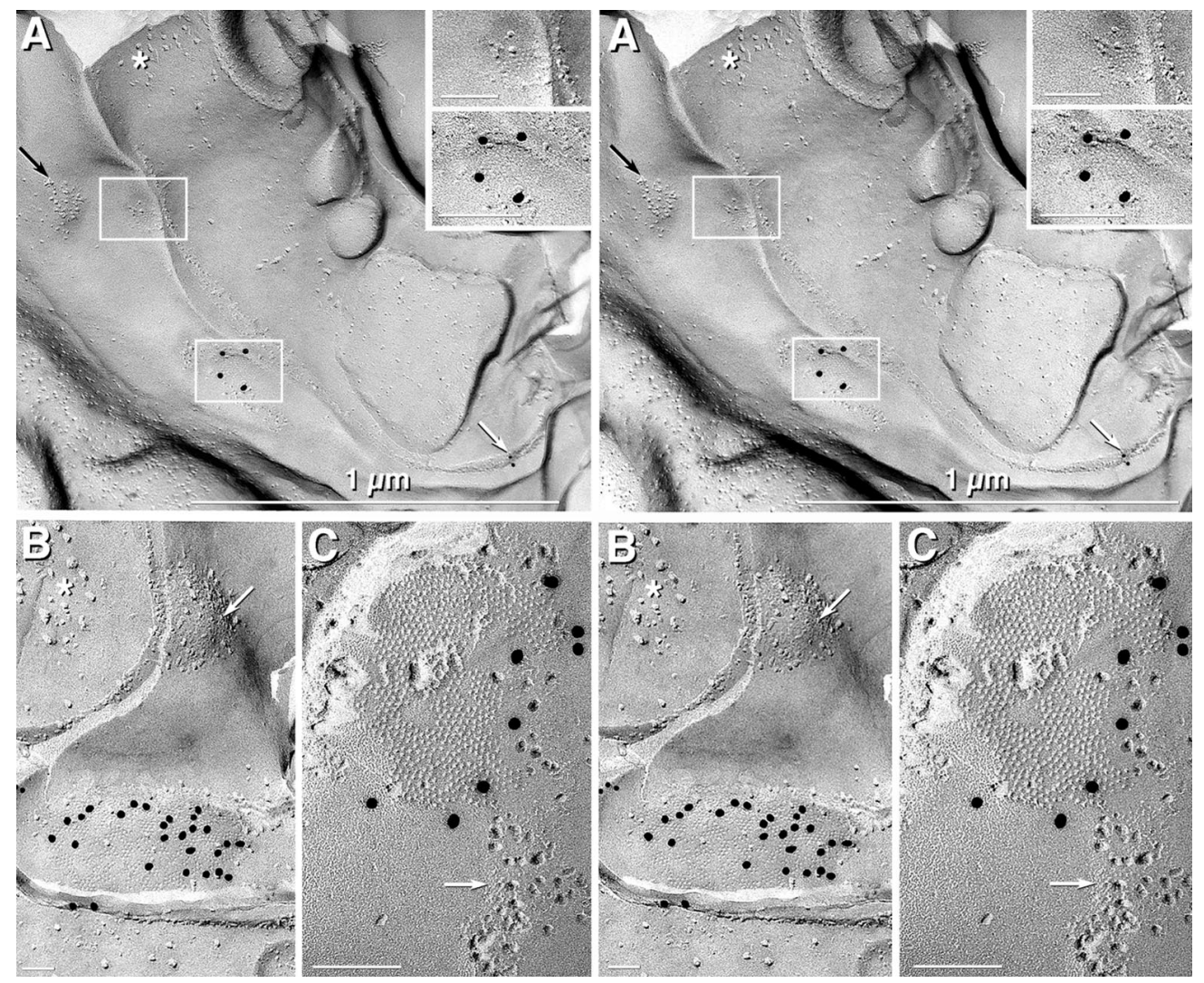

Figure 8. Identification of astrocytes as oligodendrocyte coupling partners in suprachiasmatic nucleus $(A, B)$ and spinal cord $(C) . A$, Stereoscopic image of an oligodendrocyte linked to the same astrocyte by one unlabeled gap junction (top left box, enlarged in top right inset) and by one $\mathrm{Cx} 43$-labeled gap junction $(20 \mathrm{~nm}$ gold; bottom left box, enlarged in bottom right inset). The coupled astrocyte contained a small bundle of GFAP filaments in the cross-fractured cytoplasm (asterisk), and a square array was labeled for AQP4 (10 nm gold beads; white arrow). In oligodendrocyte E-faces, reciprocal patches (black arrow) contain both IMPs and pits. $B$, Stereoscopic image of one Cx43-labeled gap junction and one unlabeled mixed gap junction/reciprocal patch (arrow) in an oligodendrocyte E-face. GFAP filaments are in the cross-fractured cytoplasm (asterisk). C, Stereoscopic image of a gap junction in a spinal cord oligodendrocyte E-face in a sample that was double-labeled for Cx32 (10 nm gold; none present) and $\mathrm{Cx30}$ (20 nm gold). Only Cx30 labeling was present in the plasma membrane of the oligodendrocyte coupling partner. Gap junctions often abut or intermingle with reciprocal patches (arrow). the plasma membrane of the coupled cell had astrocytic AQP4 arrays (Fig. $8 \mathrm{~A}$ ), or because the fracture plane had been diverted into the cytoplasm of the subjacent coupled cell, where it exposed astrocytic GFAP filaments (Fig. $8 A, B$ ). Thus, of the unlabeled $11 \%$ of gap junctions in oligodendrocyte E-faces, most ( $8 \%$ ) were identified as heterologous oligodendrocyte-to-astrocyte gap junctions on the basis of immunocytochemical or ultrastructural features. Only 3\% remained unidentified, in most cases because no portion of the coupling partner was visible in the replica. Therefore, in samples used for quantitative analysis, $>97 \%$ of oligodendrocyte gap junctions were shared with astrocytes, and none were detected linking with other oligodendrocytes or with neurons. Conversely, in single- and double-labeled samples, none of the oligodendrocyte myelin coupling partners were labeled for Cx32 or Cx36, and most (98\%) were labeled for Cx30 and/or $\mathrm{Cx} 43$, suggesting that internodal myelin shares intercellular gap junctions only with astrocytes.

With the above search strategy, a small number of oligodendrocyte-to-oligodendrocyte gap junctions could have gone unnoticed, particularly if unusual cell pairings had gone unexamined. To maximize the possibility of finding homologous oligodendrocyte-to-oligodendrocyte gap junctions, replicas were searched for sites in which two oligodendrocyte somata were in direct contact. Chains and clusters of oligodendrocytes occur in and near white matter tracts, and their directly contacting somata are frequently linked by elaborate tight junctions, often with gap junctions observed in close association with the tight junction strands (Massa and Mugnaini, 1982; Mugnaini, 1986). If oligodendrocyte-to-oligodendrocyte gap junctions exist, these oligodendrocyte pairs whose membranes are in molecular contact over large areas would seem to provide the best opportunity for formation of gap junctions. However, unlike the junctional complexes in liver and pancreas (Friend and Gilula, 1972; Wolburg and Rohlmann, 1995), strands of oligodendrocyte-tooligodendrocyte tight junctions were never observed to enclose or surround gap junctions (Fig. $7 B$ ), which would have constituted documentation of oligodendrocyte-to-oligodendrocyte gap junctions. Instead, gap junctions were observed outside of areas enclosed by tight junction strands, often at distances of $<1 \mu \mathrm{m}$ (Fig. $7 A, D)$. After FRIL, the cellular coupling partners for these tight junction-associated gap junctions were consistently labeled for Cx43 (Fig. $7 F$ ), as were gap junctions at slightly greater distances from the tight junctions (Fig. $7 C-E$ ). In contrast, none of the tight junction-associated gap junctions in oligodendrocyte E-faces were labeled for $\mathrm{Cx} 32$. Thus, close cellular apposition in areas linked by tight junctions did not result in formation of homologous oligodendrocyte-to-oligodendrocyte gap junctions.

\section{Cx36 present on both sides of neuronal gap junctions; Cx32 not found on either side}

In replicas of retina, brain, and spinal cord that were single- or double-labeled for $\mathrm{Cx} 36,271$ neuronal gap junctions were detected, 259 of which were labeled (96\%; Table 3; Fig. 10). Many of these were in confirmed neuronal E-faces coupling with cells identified as neurons because they expressed Cx36 (Fig. 10) or had other ultrastructural markers of neurons (data not shown). Labeled and unlabeled neuronal gap junctions consisted of plaques of connexons (inferior olive, Fig. $10 A$; spinal cord, data not shown; and retina, Fig. $10 B$ ) or linear strands of connexons (retina, data not shown). In contrast, in 229 replicas that were single-, double-, or triple-labeled for $\mathrm{Cx} 30, \mathrm{Cx} 32$, and $\mathrm{Cx} 43$ and in which $>3500$ labeled gap junctions were identified, no gap junction in neurons or their coupling partners was labeled for any of these confirmed glial 
Figure 9. Oligodendrocyte-to-astrocyte gap junctions in myelin from suprachiasmatic nucleus after labeling for $\mathrm{Cx} 43(A)$ and in oligodendrocyte plasma membrane from supraoptic nucleus after double labeling for $\mathrm{Cx} 43$ and $\mathrm{C} \times 30(B) . A$, Small gap junction on outer myelin plasma membrane E-face labeled for Cx43 by four $20 \mathrm{~nm}$ gold beads (enlarged in adjacent inset). Continuity of the E-face (arrow labeled $E$ ) may be traced from the outer layer of myelin (My) to the gap junction. Outer myelin membrane had IMP-free areas and reciprocal patches. Tight junction strands (white arrows) linked a small patch of the second layer of myelin to the outer layer of myelin. $B$, Four gap junctions $(1-4)$ in somatic plasma membrane of an oligodendrocyte after double labeling for $\mathrm{Cx} 43$ (20 nm gold beads) and Cx30 (10 nm gold beads). Two small gap junctions $(2,3)$ were not labeled, and one (4) was labeled by only two $10 \mathrm{~nm}$ gold beads (Cx30). Oligodendrocyte myelin E-faces are almost devoid of IMPs.

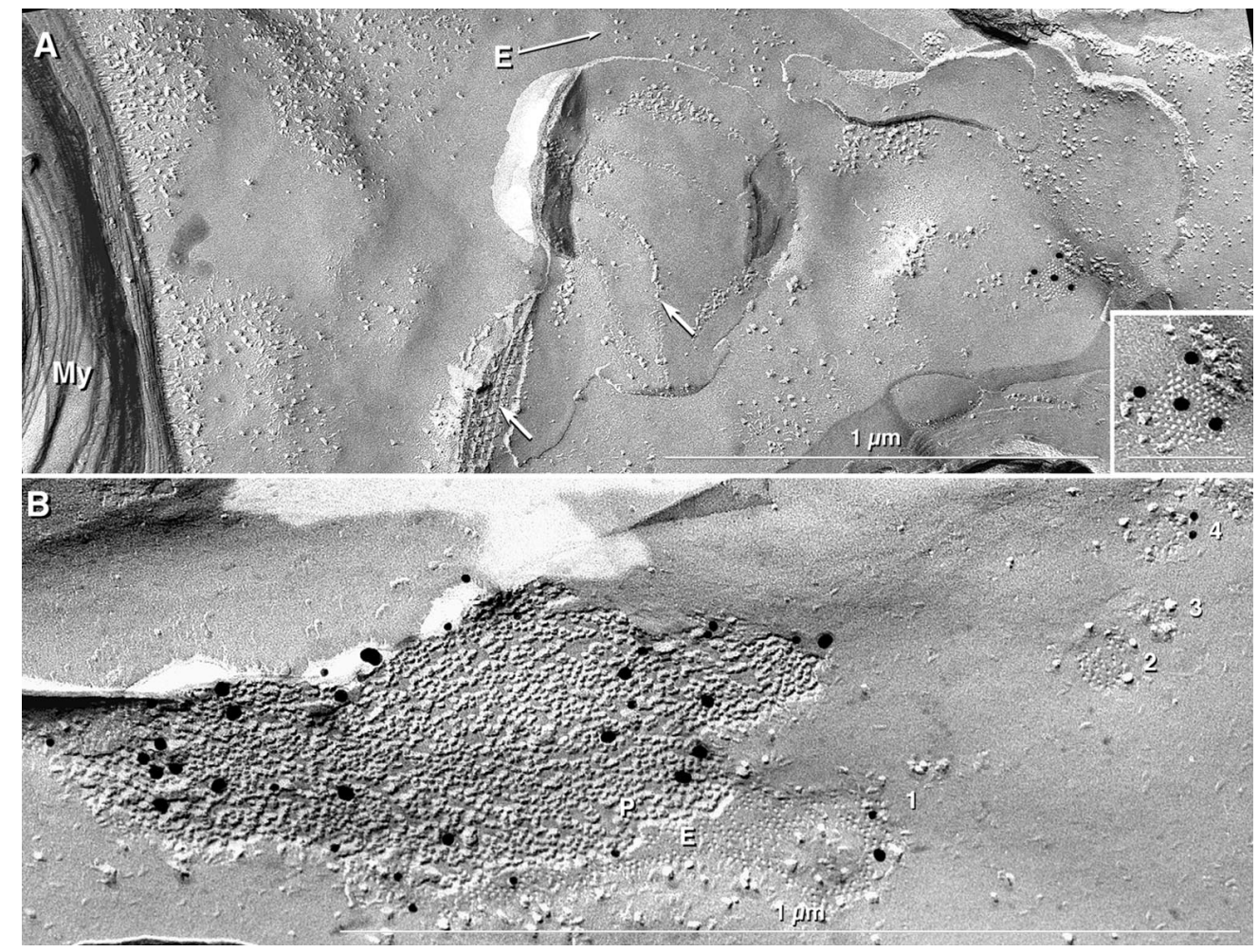

connexins. Finally, in these labeled replicas, in $>300$ unlabeled replicas examined previously (Rash et al., 1998b), as well as in all published freeze-fracture studies, neither we nor any other group has found a neuron whose coupling partner exhibited ultrastructural markers of oligodendrocytes or astrocytes (see Waxman and Pappas, 1971; Massa and Mugnaini, 1982; Landis et al., 1983; Mugnaini, 1986; Rash et al., 1997). Thus, by FRIL and conventional freeze-fracture, we found no evidence of neuron-to-glial gap junctions.

\section{DISCUSSION}

This study addresses several issues regarding the organization and composition of glial and neuronal gap junctions. In contrast to predictions of the shared-connexins/mixed-coupling hypothesis (Nadarajah et al., 1996; Alvarez-Maubecin et al., 2000), gap junctions in each of three cell types (oligodendrocytes, astrocytes, and neurons) were shown to contain a limited subset from among the four connexins examined. Cx32 was only in oligodendrocyte gap junctions, $\mathrm{Cx} 30$ and $\mathrm{Cx} 43$ were only in astrocytes, and $\mathrm{Cx} 36$ was only in neurons. Using these data for cell-specific connexin labeling, in combination with distinctive ultrastructural features to confirm cell identifications, we found that (1) oligodendrocytes shared intercellular gap junctions only with astrocytes, but not detectably with other oligodendrocytes, (2) astrocytes shared gap junctions with astrocytes and oligodendrocytes, but not with neurons, and (3) neurons shared gap junctions with other neurons, but not with oligodendrocytes or with astrocytes (Fig. 11).

These conclusions were based on unique investigative advantages of FRIL. (1) Multiple immunogold beads were localized to an easily recognized structural feature that has clearly defined borders, (2) connexons from each of two coupled cells are always separated during cleaving, which allowed unambiguous identification of the connexin(s) present in each cell, uncontaminated by connexins of its cellular coupling partner, and (3) by double or triple labeling, many gold beads of a specific size were found on most gap junctions of one cell type and, simultaneously, were absent from all gap junctions of other cell types, thereby confirming the cell specificity of connexin expression as well as providing independent tests for false positives and false negatives. Consequently, after the cell specificities of connexin expression were determined by FRIL, LM immunocytochemical experiments using cell-specific double-labeling methods revealed the abundance and subcellular distribution of gap junctions linking each cell type.

\section{Evidence that oligodendrocytes share gap junctions only with astrocytes}

Early freeze-fracture studies found that oligodendrocytes shared gap junctions only with astrocytes (Massa and Mugnaini, 1982; Mugnaini, 1986). However, $<5 \%$ of oligodendrocyte coupling partners could be identified by conventional freeze-fracture because replicated portions of oligodendrocyte coupling partners were usually too small to include defining features (Mugnaini, 1986; Rash et al., 1997). Thus, unknown systematic artifacts of cleaving could have skewed results so that oligodendrocyte-toastrocyte coupling pairs were recognized but oligodendrocyte-tooligodendrocyte or oligodendrocyte-to-neuron coupling pairs were not detected. On the basis of the demonstration that each of four connexins was cell specific and could be used as markers for cell identification (this report), the number of cell pairs in which both cells were identified was increased to $>97 \%$, thereby allowing for accurate determination of relative frequencies of cellular coupling partners among neurons and glia. By the use of two complementary searching methods, $\mathrm{Cx} 32$ was localized to the oligodendrocytic side but not to the coupling-partner side of gap junctions formed by oligodendrocytes, extending previous data for cell-specific intercellular coupling of oligodendrocytes with astrocytes (Li et al., 1997). However, the present study did not address the composition of autologous gap junctions between 

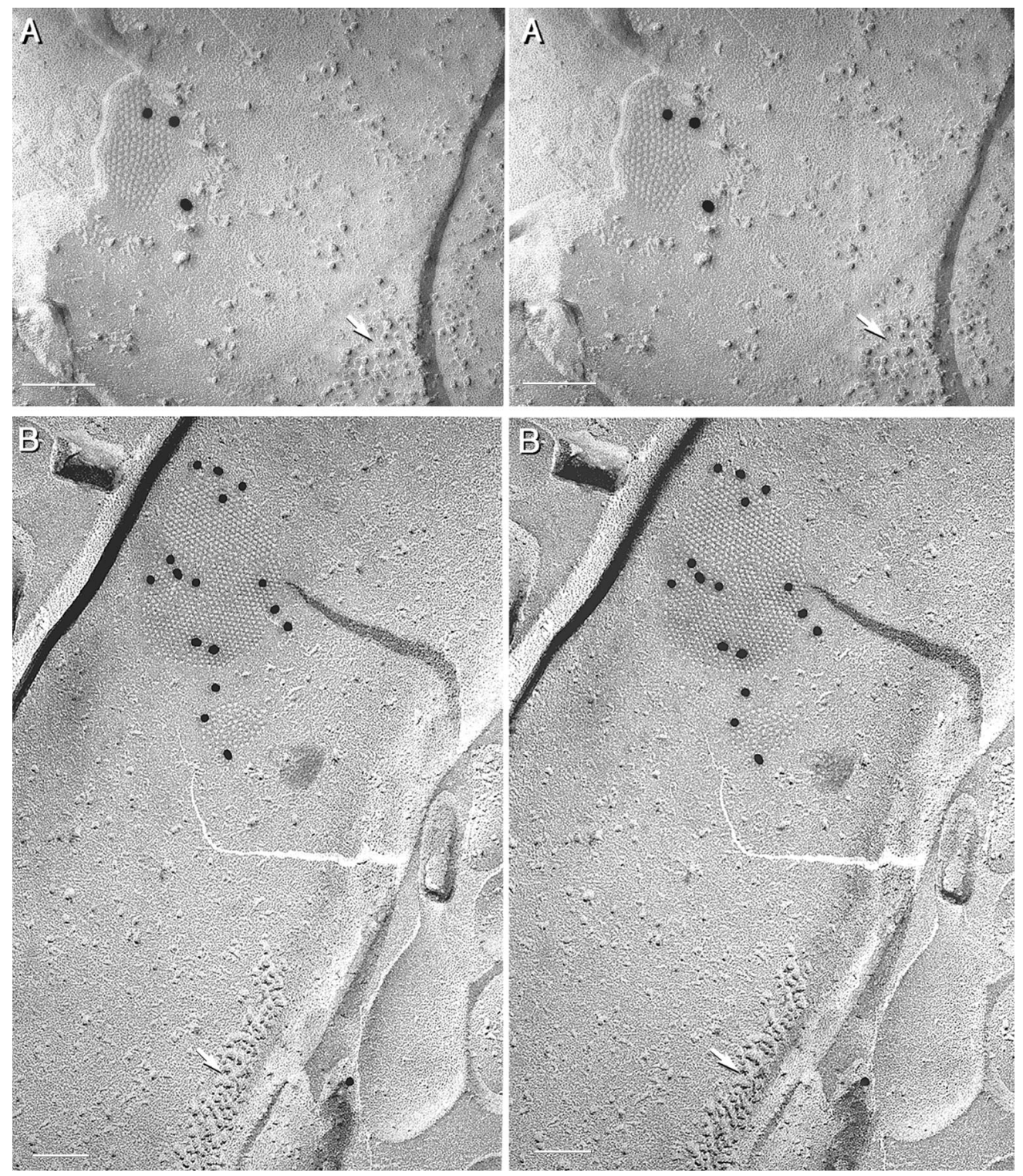

Figure 10. Stereoscopic images of Cx36-labeled neuronal gap junctions in inferior olive $(A)$ and retina $(B) . A$, Neuronal gap junction labeled for $\mathrm{Cx} 36$ by three $20 \mathrm{~nm}$ gold beads. Postsynaptic density (arrow) is a useful marker for identifying neuronal plasma membranes in freeze-fracture replicas (Rash et al., 1997, 2000). C, Two Cx36-labeled gap junctions in a nerve terminal in rat retina. Postsynaptic density (arrow) is indicated. successive layers of myelin (Sandri et al., 1977; Scherer et al., 1995).

Weak electrical coupling and limited dye transfer between oligodendrocytes have been observed in culture (Kettenmann and Ransom, 1988), in optic nerve (Butt and Ransom, 1989), and in gray matter of early postnatal spinal cord slices, with no demonstrable dye coupling of oligodendrocytes in white matter regions (Pastor et al., 1998). Moreover, asymmetric or functionally rectified coupling of oligodendrocytes with astrocytes occurs in retinal glial cells (Robinson et al., 1993) and in spinal cord gray matter (Pastor et al., 1998). As noted by Pastor et al. (1998), these observations of dye coupling between oligodendrocytes are consistent with ultrastructural evidence that adjacent oligodendrocytes share numerous gap junctions with astrocytes, which serve as "intermediaries" between successive oligodendrocytes, thereby permitting otherwise isolated oligodendrocytes to participate in gap junction intercellular communication within the broader panglial syncytium (Mugnaini, 1986; Rash et al., 1997). The hypothesis that oligodendrocytes represent "blind-ended side branches" of the glial syncytium, coupled to other oligodendrocytes only via astrocyte intermediaries, arose because of the proposed absence of oligodendrocyte-to-oligodendrocyte gap junctions and the abundance of oligodendrocyte-to-astrocyte junctions (Mugnaini, 1986). This report provides further support for the hypothesis of restricted coupling of oligodendrocytes with astrocytes. The large area of oligodendrocyte myelin around multiple axons, together with minimal cytoplasm within the myelin sheaths, may require communication via gap junctions that connect myelin to the syncytial pool of astrocytes yet allow the requisite functional isolation of each oligodendrocyte and its myelinating segments from other oligodendrocytes (Fig. 11).

\section{Neuronal gap junctions and neuronal coupling partners}

In classical ultrastructural studies that used strict criteria for designating close membrane appositions as gap junctions, the number of neuron-to-neuron gap junctions was found to be low in most areas of the CNS (Brightman and Reese, 1969; Sloper, 1972; Sotelo and Korn, 1978), and until recently, neuron-toglial cell gap junctions had never been reported. Likewise, early functional studies found evidence of only limited electrical or tracer coupling between neurons and no evidence of 


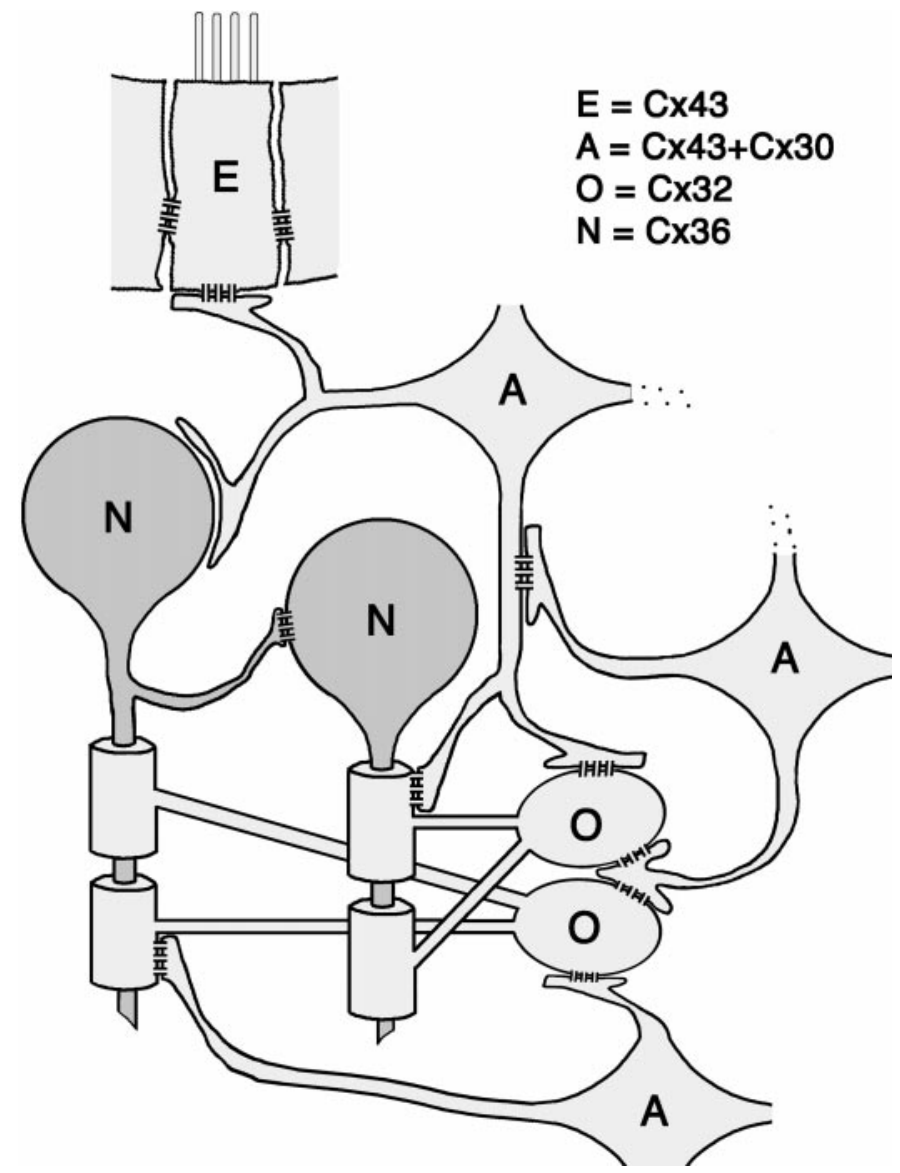

Figure 11. Diagram illustrating cellular coupling partners and connexin constituents in their gap junctions, as identified by FRIL. The cells linked within the glial syncytium are indicated by light gray shading. Astrocytes $(A)$ share gap junctions with ependymocytes $(E)$, oligodendrocytes $(O)$, and other astrocytes. Ependymocyte-to-ependymocyte $(E)$ gap junctions contain $\mathrm{Cx} 43$ but not $\mathrm{Cx} 30, \mathrm{Cx} 32$, or $\mathrm{Cx} 36$. Astrocyte gap junctions contain $\mathrm{Cx} 43$ and $\mathrm{Cx} 30$ but not $\mathrm{Cx} 32$ or $\mathrm{Cx} 36$. Oligodendrocytes $(O)$ share gap junctions only with astrocytes; the oligodendrocyte sides of these junctions contain $\mathrm{Cx} 32$ but not $\mathrm{Cx} 30, \mathrm{Cx} 36$, or $\mathrm{Cx} 43$. Neurons $(N)$ share gap junctions with other neurons and not with astrocytes or oligodendrocytes. Neuronal gap junctions contain Cx36 but not Cx30, Cx32, or Cx43.

direct neuron-to-glial dye transfer (for review, see Dudek et al., 1998). Our data confirm those early views, including the view that neuronal/glial coupling occurs by means other than gap junctions (Parpura et al., 1994; Hassinger et al., 1995; Charles et al., 1996). However, recent studies have concluded that neuron-to-neuron and neuron-to-glial gap junctions are abundant, representing $18 \%$ or even $57 \%$ of total gap junctions in cerebral cortex and locus coeruleus (Nadarajah et al., 1996; Alvarez-Maubecin et al., 2000). A single gold bead denoting Cx32 immunoreactivity was reported on either or both sides of those putative neuron-to-neuron and neuron-to-glia gap junctions, but similar low levels of $\mathrm{Cx} 32$ labeling were also reported at glial gap junctions (Alvarez-Maubecin et al., 2000). By comparison, we found previously that (1) multiple immunogold beads (as many as 50) were at a uniform distance $(<20$ $\mathrm{nm}$ ) from either or both sides of apposed glial membranes, (2) labeled areas of membranes were precisely parallel, with uniform separations of $<3 \mathrm{~nm}$, and were of distinctly increased electron density as compared with nonlabeled membranes, and (3) the thin-section images included sufficient area to provide comparative evidence of low nonspecific background labeling (Nagy et al., 1999). The current data from FRIL confirm and extend our descriptions from TEM immunocytochemistry.

\section{Connexin coexistence and heterotypic coupling}

On the basis of the high proportion of oligodendrocyte gap junctions (containing $\mathrm{Cx} 32$ ) coupling with astrocytes (containing Cx30 and Cx43), most oligodendrocyte gap junctions are both heterologous (i.e., involve two different types of cells) and heterotypic (i.e., contain two or more different connexins). Supporting data from LM immunocytochemistry include images showing that astrocytes in vivo and in vitro express both $\mathrm{Cx} 30$ and $\mathrm{Cx} 43$ and that $\mathrm{Cx} 32$ is closely associated with $\mathrm{Cx} 43$ - and Cx30-positive puncta on oligodendrocyte somata (Yamamoto et al., 1990a; Li et al., 1997; Nagy et al., 1997, 1999; Ochalski et al., 1997). However, recent reports suggest that oligodendrocytes express not only Cx32 but also Cx45 (Dermietzel et al., 1997; Kunzelmann et al., 1997) and that astrocytes express not only $\mathrm{Cx} 30$ and $\mathrm{Cx} 43$ but also Cx45 and Cx26 (Dermietzel, 1998; Alvarez-Maubecin et al., 2000). Although we concur that astrocytes also express Cx26, our studies of Cx45 in the CNS remain inconclusive (J. I. Nagy and J. E. Rash, unpublished observations). In any case, oligodendrocyte-to-astrocyte gap junctions may contain as many as five different connexins in the apposing plaques, with $\mathrm{Cx} 32$ and $\mathrm{Cx} 45$ in the oligodendrocyte side coupling with $\mathrm{Cx} 30, \mathrm{Cx} 43$, and $\mathrm{Cx} 26$ and possibly $\mathrm{Cx} 45$ in the astrocyte side. Precedent for three connexins in individual gap junction hemiplaques has been shown by FRIL in heart (Severs, 1999).

The presence of $\mathrm{Cx} 43$ and $\mathrm{Cx} 30$ in the astrocyte side of oligodendrocyte-to-astrocyte gap junctions and $\mathrm{Cx} 32$ in the oligodendrocyte side is especially noteworthy because $\mathrm{Cx} 43$ is reported not to form functional channels with $\mathrm{Cx} 32$ when expressed in oocytes (Elfgang et al., 1995; White et al., 1995). Thus, oligodendrocytic Cx32 may form channels with astrocytic $\mathrm{Cx} 30$, and oligodendrocytic $\mathrm{Cx} 45$ may pair with astrocytic $\mathrm{Cx} 43$, both of which are permissive combinations (White and Bruzzone, 1996). Regardless, it is essential to determine whether oligodendrocyte or astrocyte gap junction plaques contain $\mathrm{Cx} 45$ and whether, in addition to forming channels with $\mathrm{Cx} 43$, oligodendrocyte $\mathrm{Cx} 45$ also forms functional channels with astrocytic Cx30.

\section{Functional considerations and unresolved issues}

The functional requirement for multiple connexins at glial gap junctions may allow for different conductance properties at different subcellular locations, permit differential regulation of permeability state, and allow metabolic regulation by the cells on either or both sides of the gap junctions (White et al., 1995; Bruzzone et al., 1996; Veenstra, 1996; White and Bruzzone, 1996). Thus, the several connexin constituents and particular connexin pairings may impart the distinctive coupling properties that have been observed both in vivo and in vitro at oligodendrocyte-to-astrocyte gap junctions (Kettenmann and Ransom, 1988; Butt and Ransom, 1989; Moreno et al., 1991; Giaume and Venance, 1995; Sontheimer, 1995). These may include directionality with which substances pass through gap junctions, the low efficiency and variability observed for oligodendrocyte dye coupling, and molecular size and charge selectivity in channel permeation (Robinson et al., 1993; Veenstra, 1996; Pastor et al., 1998). Identification of all connexins expressed at glial gap junctions will ultimately lead to a better understanding of the functional role of the proposed panglial syncytium in adult mam- 
malian CNS and, in particular, the basis for cell specificity of connexin expression and for the exclusive sharing of intercellular oligodendrocyte gap junctions with astrocytes.

\section{REFERENCES}

Alvarez-Maubecin V, García-Hernández F, Williams JT, Van Bockstaele EJ (2000) Functional coupling between neurons and glia. J Neurosci 20:4091-4098.

Berdan RC, Shivers RR, Bulloch AGM (1987) Chemical synapses, particle arrays, pseudo-gap junctions and gap junctions of neurons and glia in the buccal ganglion of Helisoma. Synapse 1:304-323.

Brightman MW, Reese TS (1969) Junctions between intimately apposed cell membranes in the vertebrate brain. J Cell Biol 40:648-677.

Bruzzone R, White TW, Paul DL (1996) Connections with connexins: the molecular basis of direct intercellular signaling. Eur $\mathrm{J}$ Biochem 238:1-27.

Butt AM, Ransom BR (1989) Visualization of oligodendrocytes and astrocytes in the intact rat optic nerve by intracellular injection of Lucifer yellow and horseradish peroxidase. Glia 2:470-475.

Charles AC, Kodali SK, Tyndale RF (1996) Intercellular calcium waves in neurons. Mol Cell Neurosci 7:337-353.

Condorelli DF, Parenti R, Spinella F, Salinaro AT, Belluardo N, Cardile V, Cicirata F (1998) Cloning of a new gap junction gene (Cx36) highly expressed in mammalian brain neurons. Eur J Neurosci 10:1202-1208.

Dermietzel R (1998) Diversification of gap junction proteins (connexins) in the central nervous system and the concept of functional compartments. Cell Biol Int 22:719-730.

Dermietzel R, Spray DC (1998) From neuro-glue ("nervenkitt") to glia: a prologue. Glia 24:1-7.

Dermietzel R, Farooq M, Kessler JA, Hertzberg EL, Spray DC (1997) Oligodendrocytes express gap junction proteins connexin32 and connexin45. Glia 20:101-114.

Dudek FE, Yasumura T, Rash JE (1998) Nonsynaptic mechanisms in seizures and epileptogenesis. Cell Biol Int 22:793-805.

Elfgang C, Eckert R, Lichthenberg-Frate H, Butterweck A (1995) Specific permeability and selective formation of gap junction channels in connexin-transfected HeLa cells. J Cell Biol 129:805-817.

Friend DS, Gilula NB (1972) Variations in tight and gap junctions in mammalian tissues. J Cell Biol 53:758-776.

Fujimoto K (1995) Freeze-fracture replica electron microscopy combined with SDS digestion for cytochemical labeling of integral membrane proteins. Application to the immunogold labeling of intercellular junctional complexes. J Cell Sci 108:3443-3449.

Giaume C, Venance L (1995) Gap junctions in brain glial cells and development. Perspect Dev Neurobiol 2:335-345.

Hassinger TD, Atkinson PB, Strecker GJ, Whalen LR, Dudek FE, Kossell AH, Kater SB (1995) Evidence for glutamate-mediated activation of hippocampal neurons by glial calcium waves. J Neurobiol 28:159-170.

Hatton JD, Ellisman MH (1981) The distribution of orthogonal arrays and their relationship to intercellular junctions in neuroglia of the freeze-fractured hypothalamo-neurohypophysial system. Cell Tissue Res 215:309-323.

Hudson CS, Rash JE, Shinowara N (1981) Freeze-fracture and freezeetch methods. In: Current trends in morphological techniques, Vol II (Johnson JE, ed), pp 183-217. Boca Raton, FL: CRC.

Kettenmann H, Ransom BR (1988) Electrical coupling between astrocytes and between oligodendrocytes studied in mammalian cell cultures. Glia 1:64-73.

Kunzelmann P, Blumcke I, Traub O, Dermietzel R, Willecke K (1997) Coexpression of connexin 45 and -32 in oligodendrocytes of rat brain. J Neurocytol 26:17-22.

Landis DMD (1981) Membrane structure in mammalian astrocytes: a review of freeze-fracture studies on adult, developing, reactive and cultured astrocytes. J Exp Biol 95:35-48.

Landis DMD, Weinstein LA, Halperin JJ (1983) Development of synaptic junctions in cerebellar glomeruli. Dev Brain Res 8:231-245.

Li J, Hertzberg EL, Nagy JI (1997) Connexin32 in oligodendrocytes and association with myelinated fibers in mouse and rat brain. J Comp Neurol 379:571-591.

Massa PT, Mugnaini E (1982) Cell junctions and intramembrane particles of astrocytes and oligodendrocytes: a freeze-fracture study. Neuroscience 7:523-538.

Micevych PE, Abelson L (1991) Distribution of mRNAs coding for liver and heart gap junction proteins in the rat central nervous system. J Comp Neurol 305:96-118.

Micevych PE, Popper P, Hatton GI (1996) Connexin 32 mRNA levels in the rat supraoptic nucleus; up-regulation prior to parturition and during lactation. Neuroendocrinology 63:39-45.

Moreno AP, Campos de Carvalho AC, Verselis V, Eghbali B, Spray DC (1991) Voltage-dependent gap junction channels are formed by connexin32, the major gap junction protein of rat liver. Biophys $\mathrm{J}$ 59:920-925.
Mugnaini E (1986) Cell junctions of astrocytes, ependyma, and related cells in the mammalian central nervous system, with emphasis on the hypothesis of a generalized functional syncytium of supporting cells. In: Astrocytes, Vol I (Fedoroff S, Vernadakis A, eds), pp 329-371. New York: Academic.

Nadarajah B, Thomaidou D, Evans WH, Parnavelas JG (1996) Gap junctions in the adult cerebral cortex: regional differences in their distribution and cellular expression of connexins. J Comp Neurol 376:326-342.

Nagy JI, Rash JE (2000) Connexins and gap junctions of astrocytes and oligodendrocytes in the CNS. Brain Res Rev 32:29-44.

Nagy JI, Ochalski PAY, Li J, Hertzberg EL (1997) Evidence for colocalization of another connexin with connexin-43 at astrocytic gap junctions in rat brain. Neuroscience 78:533-548.

Nagy JI, Patel D, Ochalski PAY, Stelmack GL (1999) Connexin30 in rodent, cat and human brain: selective expression in gray matter astrocytes, co-localization with connexin43 at gap junctions and late developmental appearance. Neuroscience 88:447-468.

Nedergaard M (1994) Direct signaling from astrocytes to neurons in cultures of mammalian brain cells. Science 263:1768-1771.

Nielsen S, Nagelhus EA, Amiry-Moghaddam M, Bourque C, Agre P, Ottersen OP (1997) Specialized membrane domains for water transport in glial cells: high-resolution immunogold cytochemistry of aquaporin-4 in rat brain. J Neurosci 17:171-180.

Ochalski PAY, Frankenstein UN, Hertzberg EL, Nagy JI (1997) Connexin43 in rat spinal cord: localization in astrocytes and identification of heterotypic astro-oligodendrocytic gap junctions. Neuroscience 76:931-945

Parpura V, Basarky TA, Liu F, Jeftinija K, Jeftenija S, Haydon PG (1994) Glutamate-mediated astrocyte-neuron signalling. Nature 369:744-747.

Pastor A, Kremer M, Möller T, Kettenmann H, Dermietzel R (1998) Dye coupling between spinal cord oligodendrocytes: differences in coupling efficiency between gray and white matter. Glia 24:108-120.

Phillips TE, Boyne AF (1984) Liquid nitrogen-based quick freezing: experiments with bounce-free delivery of cholinergic nerve terminals to a metal surface. J Electron Microsc Tech 1:9-29.

Rash JE, Yasumura T (1999) Direct immunogold labeling of connexins and aquaporin 4 in freeze-fracture replicas of liver, brain and spinal cord: factors limiting quantitative analysis. Cell Tissue Res 296:307-321.

Rash JE, Dillman RK, Morita M, Whalen LR, Guthrie PB, Fay-Guthrie D, Wheeler DW (1995) Grid-mapped freeze fracture: correlative confocal laser scanning microscopy and freeze-fracture electron microscopy of preselected cells in tissue slices. In: Rapid freezing, freeze fracture, and deep etching (Severs NJ, Shotton DM, eds), pp 127-150. New York: Wiley.

Rash JE, Dillman RK, Bilhartz BL, Duffy HS, Whalen LR, Yasumura T (1996) Mixed synapses discovered and mapped throughout mammalian spinal cord. Proc Natl Acad Sci USA 93:4235-4239.

Rash JE, Duffy HS, Dudek FE, Bilhartz BL, Whalen LR, Yasumura T (1997) Grid-mapped freeze-fracture analysis of gap junctions in gray and white matter of adult rat central nervous system, with evidence for a "panglial syncytium" that is not coupled to neurons. J Comp Neurol 388:265-292.

Rash JE, Yasumura T, Dudek FE (1998a) Ultrastructure, histological distribution, and freeze-fracture immunocytochemistry of gap junctions in rat brain and spinal cord. Cell Biol Int 22:731-749.

Rash JE, Yasumura T, Hudson CS, Agre P, Nielsen S (1998b) Direct immunogold labeling of aquaporin-4 in "square arrays" of astrocyte and ependymocyte plasma membranes in rat brain and spinal cord. Proc Natl Acad Sci USA 95:11981-11986.

Rash JE, Staines WA, Yasumura T, Patel D, Hudson CS, Stelmack GL, Nagy JI (2000) Immunogold evidence that neuronal gap junctions in adult rat brain and spinal cord contain connexin36 (Cx36) but not $\mathrm{Cx} 32$ or Cx43. Proc Natl Acad Sci USA 97:7573-7578.

Robinson SR, Hampson ECGM, Munro MN, Vaney DI (1993) Unidirectional coupling of gap junctions between neuroglia. Science 262:1072-1074.

Sandri C, Van Buren JM, Akert K (1977) Membrane morphology of the vertebrate nervous system. Prog Brain Res 46:1-384.

Scherer SS, Deschenes SM, Xu Y-T, Grinspan JP, Fischbeck KH, Paul DL (1995) Connexin32 is a myelin-related protein in the PNS and CNS. J Neurosci 15:8281-8284.

Severs NJ (1999) Cardiovascular disease. Novartis Found Symp 219:188-206.

Sloper JJ (1972) Gap junctions between dendrites in the primate cortex. Brain Res 44:641-646.

Sontheimer H (1995) Coupling in glial cells: who is coupled, and why? The Neuroscientist 1:188-191.

Sotelo C, Korn H (1978) Morphological correlates of electrical and other interactions through low-resistance pathways between neurons of the vertebrate central nervous system. Int Rev Cytol 55:67-107. 
Veenstra RD (1996) Size and selectivity of gap junction channels formed from different connexins. J Bioenerg Biomembr 28:327-337.

Waxman SG, Black JA (1984) Freeze-fracture ultrastructure of the perinodal astrocyte and associated glial junctions. Brain Res 308:77-87.

Waxman SG, Pappas GD (1971) An electron microscopic study of synaptic morphology in the oculomotor nuclei of three inframammalian species. J Comp Neurol 143:41-72.

White T, Paul D, Goodenough DA, Bruzzone R (1995) Functional analysis of selective interactions among rodent connexins. Mol Biol Cell $6: 459-470$.

White TW, Bruzzone R (1996) Multiple connexin proteins in single intercellular channels: connexin compatibility and functional consequences. J Bioenerg Biomembr 28:339-350.
Wolburg H, Rohlmann A (1995) Structure-function relationships in gap junctions. Int Rev Cytol 157:315-373.

Wolff JR, Stuke K, Missler M, Tytko H, Schwarz P, Rohlmann A, Chao TL (1998) Autocellular coupling by gap junctions in cultured astrocytes: a new view on cellular autoregulation during process formation. Glia $24: 121-140$

Yamamoto T, Ochalski A, Hertzberg EL, Nagy JI (1990a) LM and EM immunolocalization of the gap junctional protein connexin43 in rat brain. Brain Res 508:313-319.

Yamamoto T, Ochalski A, Hertzberg EL, Nagy JI (1990b) On the organization of astrocytic gap junctions in the brain as suggested by LM and EM immunocytochemistry of connexin 43 expression. J Comp Neurol $302: 853-883$ 